\title{
Two-Phase Non-Equilibrium Models: the Challenge of Improving Phase Change Heat Transfer Prediction
}

Departamento de Engenharia Mecânica Universidade Federal de Santa Catarina 88040-900 Florianópolis, SC. Brazil jrb@nrva.ufsc.br
This lecture addresses some recent developments in modelling of macroscopic thermodynamic and hydrodynamic non-equilibrium phenomena in convective phase change (boiling and condensation) of pure fluids and mixtures. Proper accounting of such phenomena may hold the key to explain and predict deviations from the classical (equilibrium) phase change convective heat transfer behaviour reported in the literature and yet not fully understood.

In the first part of the paper, a detailed qualitative description of the classical heat transfer coefficient behaviour is presented together with two examples of departure from macroscopic equilibrium largely supported by experimental evidence. The second part of the paper reviews successful attempts to model the non-equilibrium phase change phenomena taking place in the two situations.

The first example is a thermodynamic non-equilibrium slug flow model (one in which saturated Taylor bubbles become separated by slugs of subcooled liquid) that predicts the peaks in heat transfer coefficient at near-zero thermodynamic quality observed in forced convective boiling of some pure liquids. The occurrence of such peaks is typical of low latent heat, low thermal conductivity systems and of systems in which the vapour volume formation rate for a given heat flux is large.

The second example is a comprehensive annular flow calculation methodology that predicts the decrease in the heat transfer coefficient with increasing quality observed in convective boiling of binary and multicomponent mixtures. In this case, as will be seen, coupled mass transfer resistance and hydrodynamic non-equilibrium effects generate concentration gradients between the liquid film and entrained droplets that are responsible for the heat transfer deterioration. In addition,

it will be shown that for condensation of mixtures the methodology predicts a heat transfer intensification which has been subsequently confirmed by independent experimental results.

Keywords: Two-phase flow, phase change, non-equilibrium modelling, slug flow, annular flow

\section{Introduction}

This paper is dedicated to the study of forced convective boiling of pure fluids and mixtures. Non-equilibrium models are reviewed in an attempt to explain situations in which departure from the classical (i.e., textbook) heat transfer coefficient behaviour takes place. Experimental conditions under which such deviations were observed are typical of most industrial phase change equipment.

A substantial portion of industrial heat exchange processes involve phase change at low to moderate heat fluxes (Hewitt et al., 1994), thus making phenomenological flow pattern based models for intermittent (e.g., slug) and wall film (e.g., churn and annulardispersed) flows an attractive tool for improving existing design methods traditionally built upon equilibrium correlations (Webb and Gupte, 1992; Collier and Thome, 1994).

The major challenges in flow regime based modelling are the sound interpretation of observed non-equilibrium phenomena and their adequate representation aiming at the improvement of heat transfer predictions. Two types of non-equilibrium effects will be dealt with in this lecture, namely, thermodynamic non-equilibrium, that resulting from local departures from saturation (subcooling or superheating) with implications on the distribution of phases and of phase velocities within the heated channel; and hydrodynamic nonequilibrium, that resulting from phase and phase velocities distributions within the channel (e.g., slippage and droplet

Presented at ENCIT2004 - 10th Brazilian Congress of Thermal Sciences and Engineering, Nov. 29 -- Dec. 03, 2004, Rio de Janeiro, RJ, Brazil.

Technical Editor: Atila P. Silva Freire. entrainment) with implications on the local thermodynamic balance within and between the phases.

The non-equilibrium effects treated in the present work extend from low to high qualities and are concerned with phase change of pure fluids as well as mixtures. There is, therefore, a great potential for incorporating such formulations in design methods. For instance, as pointed out by Wadekar and Kenning (1990), a considerable number of industrial reboilers operates in conditions typical of intermittent flows. Recent experimental (Urso et al., 2002) as well as modelling (Sun et al., 2004) efforts are being made to better understanding the particular features of such flows in the context of phase change equipment.

In what follows, Section 2 reviews important concepts related to the definition of thermodynamic and hydrodynamic equilibrium in forced convective flows with phase change. In Section 3, two examples extensively reported in the literature of departure from the equilibrium representation of the heat transfer coefficient behaviour in convective boiling are presented. The first example is the occurrence of heat transfer peaks in the near-zero quality region and the second example is the deterioration of heat transfer coefficient for binary and multicomponent mixtures at high qualities. Phenomenological models based on thermal and hydrodynamic nonequilibrium effects put forward by the present author and collaborators are reviewed in Sections 4 and 5. Finally, conclusions and recommendations for future work are presented in Section 6.

\section{Some Equilibrium Phase Change Definitions}

Prior to the portrayal of non-equilibrium phenomena in convective phase change, some important parameters of thermal and hydrodynamic equilibria will be described. A qualitative assessment 
of the heat transfer coefficient behaviour will be presented at the end of this section.

\section{Heat Transfer Coefficient}

The local, time-averaged heat transfer coefficient is defined as,

$$
\bar{\alpha}=\frac{\dot{q}_{w}}{\bar{T}_{w}-\bar{T}_{b}}
$$

where $\dot{q}_{w}$ is the wall heat flux, $\bar{T}_{w}$ is the local, time-averaged wall temperature and $\bar{T}_{b}$ is the local, time-averaged bulk temperature. In the region downstream of the saturation point, $\bar{T}_{b}=T_{\text {sat }}(p)$, where $p$ is the local pressure. Figure 1 illustrates the profiles of $\bar{T}_{b}$ and $T_{\text {sat }}$ for a pure fluid at constant wall heat flux.

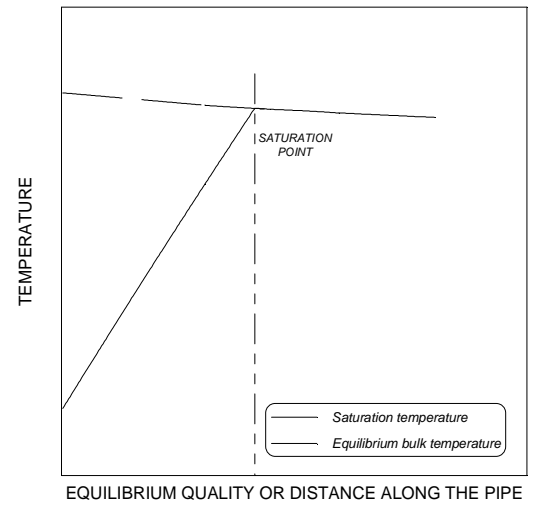

Figure 1. Bulk and saturation temperature profiles as a function of distance along the pipe. Constant wall heat flux.

In boiling of liquid mixtures, $\bar{T}_{b}$ is the local bubble-point temperature, $\bar{T}_{b u b}$. Alternatively, in condensation of vapour mixtures, $\bar{T}_{b}$ is the local dew-point temperature, $\bar{T}_{d e w}$.

\section{Quality}

The equilibrium quality is defined as,

$$
x_{e q} \equiv \frac{h-h_{L, s a t}}{h_{G, s a t}-h_{L, s a t}},
$$

where $h$ is the local specific enthalpy of the fluid (single phase or two-phase) and $h_{L, s a t}$ and $h_{G \text {,sat }}$ are the saturated liquid and vapour enthalpies, respectively. Thus, in the two-phase saturated region, $h_{L, s a t} \leq h \leq h_{G, s a t}$ and $0 \leq x_{e q} \leq 1$. In the subcooled region, $h<h_{L, s a t}$ and $x_{e q}<0$ and in the superheated region $h>h_{G, s a t}$ and $x_{e q}>0$.

The vapour dynamic mass fraction (or the real or hydrodynamic quality) is defined as the ratio of the mass flow rate of vapour and the total mass flow rate,

$$
x_{G} \equiv \frac{\dot{M}_{G}}{\dot{M}_{G}+\dot{M}_{L}} .
$$

As opposed to the equilibrium quality, the real quality varies only between 0 and 1 , and is independent of the local thermodynamic state (saturated, subcooled or superheated). The behaviour of $x_{e q}$ and $x_{G}$ as a function of enthalpy is illustrated in Figure 2 .

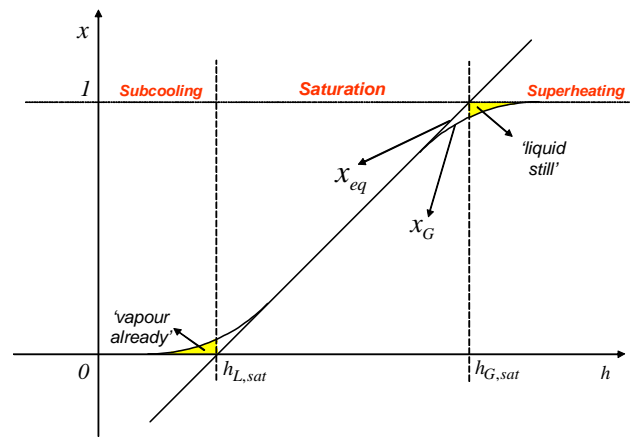

Figure 2. An illustration of the difference between the equilibrium and the real quality.

In real flows in vaporization equipment, due to radial gradients of superheat (higher temperatures near the wall), bubble generation takes place adjacent to the wall whilst the bulk is still subcooled. This explains the existence of the region labelled as "vapour already' in Figure 2. Analogously, the 'liquid still' region in Figure 2 accounts for the coexistence of superheated vapour and liquid droplets in the high quality region. In great part of the saturated region, however, there is a superposition of equilibrium and real qualities, enabling the convenient determination of vapour flow rates from energy balances. A more detailed exploration of the definitions of quality was provided by Baehr and Stephan (1998).

Regimes in Convective Boiling and the Classical Heat Transfer Coefficient Behaviour

The classical (i.e., textbook) interpretation of the flow and heat transfer problem in convective boiling is presented through an analysis of Figures 3 and 4, adapted from Collier and Thome (1994). In Figure 3, the heat transfer regimes in convective boiling are represented qualitatively as a function of enthalpy (hence equilibrium quality) and wall heat flux. Figure 4 presents the qualitative behaviour of the heat transfer coefficient as a function of equilibrium quality and of heat flux. The total mass flow rate and the pipe geometry (length and diameter) are assumed constant and, for simplicity, the pressure drop is assumed negligible.

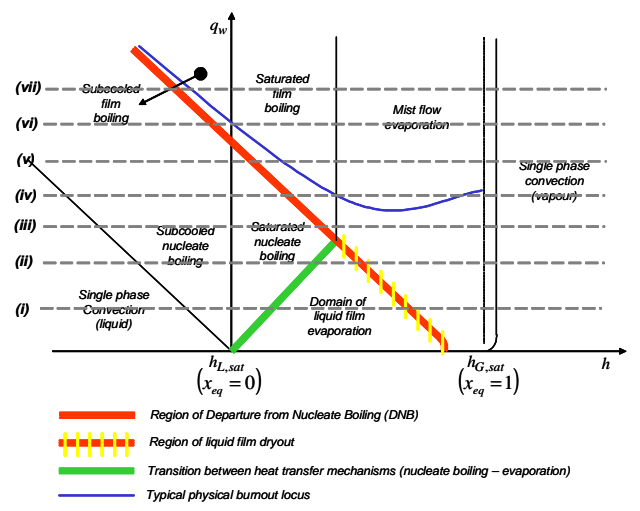

Figure 3. Two-phase forced convective heat transfer regimes as a function of equilibrium quality and heat flux (Collier and Thome, 1994). 


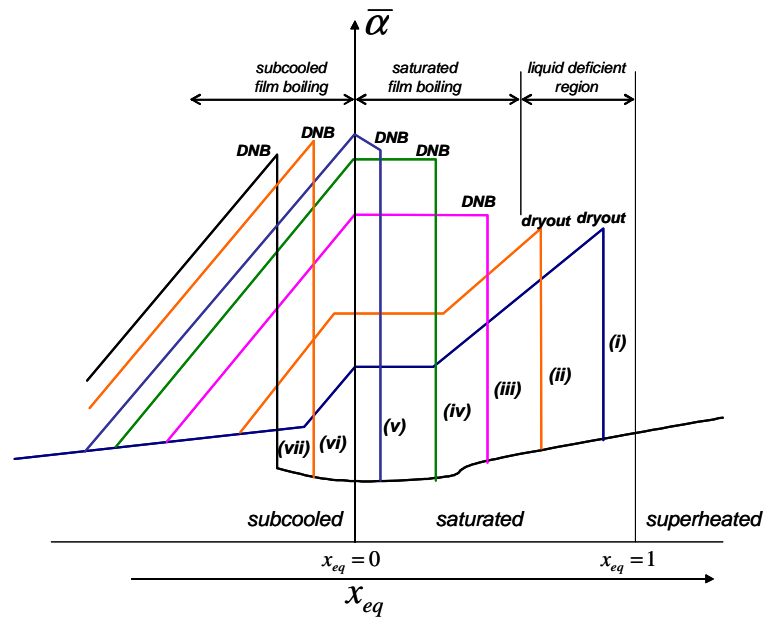

Figure 4. Qualitative heat transfer coefficient behaviour as a function of equilibrium quality and heat flux (Collier and Thome, 1994).

In Figures 3 and 4, lines (i) to (vii) represent increasing heat flux conditions. Curve (i) relates to a low heat flux condition, and together with curve (ii), envelope the (design) operating conditions of two-phase heat transfer equipment (e.g., evaporators, reboilers etc.). Flow patterns within this range of heat fluxes are typically those observed in adiabatic gas-liquid flows (i.e., bubble, slug, churn, annular and mist flows). Liquid depletion in the near wall region takes place at relatively high qualities and is associated with the phenomenon of liquid film 'dryout' (rather than the departure from nucleate boiling - DNB - typical of high heat fluxes - for more details see Collier and Thome, 1994).

All of the non-equilibrium effects reported in this paper occur within the low heat flux range of the boiling region illustrated in Figures 3 and 4 (curves $i$ and ii). In this region, starting with heat transfer to saturated liquid near the entrance of the channel, subcooled boiling is initiated giving rise to an increasing heat transfer coefficient (defined in this region as the rate of the wall heat flux to the difference between the wall temperature and the bulk temperature). After equilibrium saturation has been attained, the heat transfer coefficient (now defined as the ratio of the wall heat flux to the difference between the wall temperature and the saturation temperature) remains approximately constant and independent of quality (reflecting the dominance of nucleate boiling effects). Further downstream, as quality increases, there is a transition to a heat transfer mode dominated by forced convection and the heat transfer coefficient increases with increasing quality up to the point of critical heat flux (CHF), characterized by the 'dryout' of the liquid film.

\section{Departure from the Classical Behaviour}

As pointed out by Hewitt (2000), the representation of the heat transfer coefficient behaviour delineated in Section 2 has been the basis of design calculations for forced convective boiling for many years, with correlations being developed to represent the various regions of Figures 3 and 4 . In this section, the non-equilibrium phenomena responsible for substantial departures from this classical representation will be identified. Physical interpretations of these phenomena will be provided together with phenomenological models for their prediction.

\section{Heat Transfer Peaks at Near-Zero Qualities}

The first case of departure from the classical behaviour of convective boiling heat transfer is the occurrence of heat transfer coefficient peaks in the region of near-zero equilibrium quality. The peaks were observed in boiling of hydrocarbons (Kandlbinder, 1997; Urso et al., 2002) and of water at sub-atmospheric pressures in vertical channels (Cheah, 1995), and in boiling of refrigerants in horizontal tubes (Kattan et al., 1995; Thome, 1995).

An example of the phenomenon of near-zero quality heat transfer peaks is depicted in Figures 5 and 6. The results were obtained by Kandlbinder (1997), who was the first to investigate systematically this effect. The experiments were performed in a $0.0254 \mathrm{~mm}$ ID, $8.5 \mathrm{~m}$ long vertical tube with n-pentane, n-hexane and iso-octane (pure and mixed) and covered ranges of mass flux from 140 to $510 \mathrm{~kg} / \mathrm{m} 2 \mathrm{~s}$, of heat flux from 10 to $60 \mathrm{~kW} / \mathrm{m} 2$, of inlet subcooling from $40 \mathrm{oC}$ to $10 \mathrm{oC}$ and of pressure from 2.4 to $10 \mathrm{bar}$.

More recently, Urso et al. (2002) extended Kandlbinder's database through iso-octane boiling experiments covering total mass fluxes from 70 to $300 \mathrm{~kg} / \mathrm{m} 2 \mathrm{~s}$. They aimed at obtaining a wider equilibrium quality range inside which sub-annular flow patterns (bubble, slug and churn) would persist over larger distances along the channel. Zones of heat transfer enhancement in the near-zero quality region were observed repeatedly.

An explanation for the existence of near-zero quality peaks was pursued quantitatively by Barbosa and Hewitt (2004). According to the theory, in a situation where the conditions for bubble nucleation at the wall are poor, the layer of fluid adjacent to the wall becomes highly superheated. Therefore, once a bubble is nucleated it grows rapidly, suddenly releasing the thermal energy stored in the surrounding liquid. Under some circumstances, the rate of change in void fraction associated with bubble growth may be high enough to trigger an abrupt flow pattern transition leading to the formation of a vapour plug (Figure 7).

The postulated mechanism for the formation of the vapour plug in the subcooled region is supported by experimental evidence by Jeglic and Grace (1965), who studied the onset of flow oscillations in forced convective boiling of subcooled water at sub-atmospheric pressures in electrically heated tubes (constant wall heat flux). They observed that the flow oscillations were accompanied by a high rate of change in void fraction, whose association with the formation of a vapour slug was confirmed through visual observation of the flow structure.

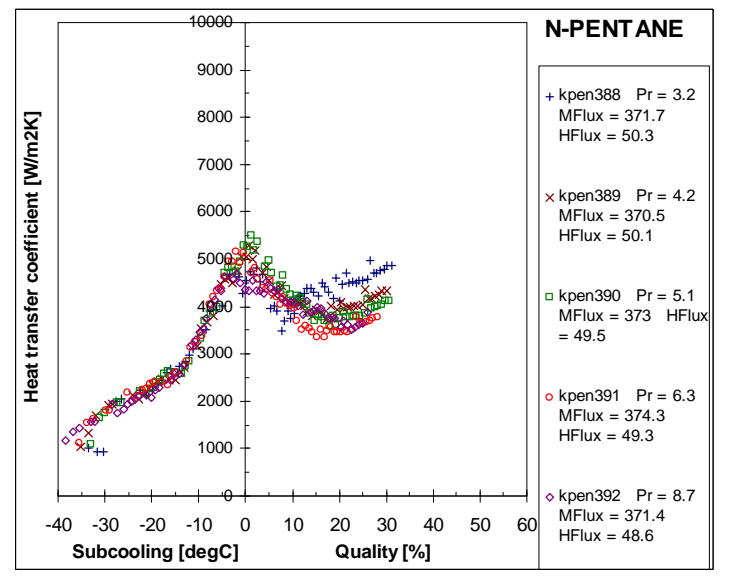

Figure 5. Heat transfer coefficient as a function of the equilibrium quality (saturated region) and of subcooling (subcooled region) in flow boiling of n-pentano (Kandlbinder, 1997). 


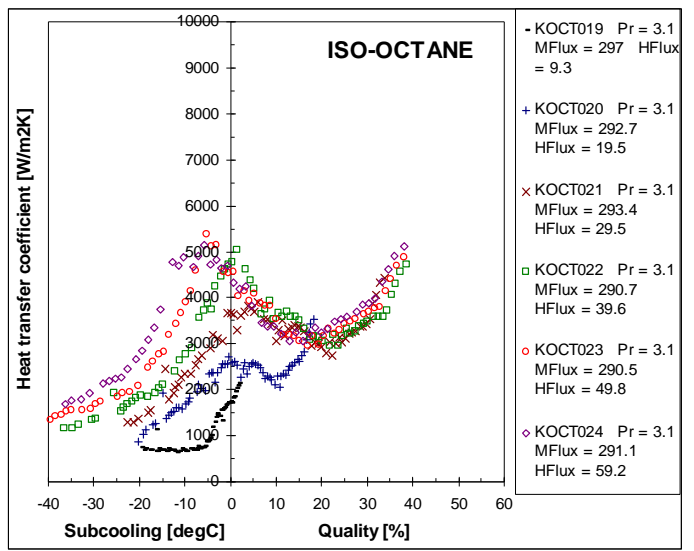

Figure 6. Heat transfer coefficient as a function of the equilibrium quality (saturated region) and of subcooling (subcooled region) in flow boiling of n-pentane (Kandlbinder, 1997).

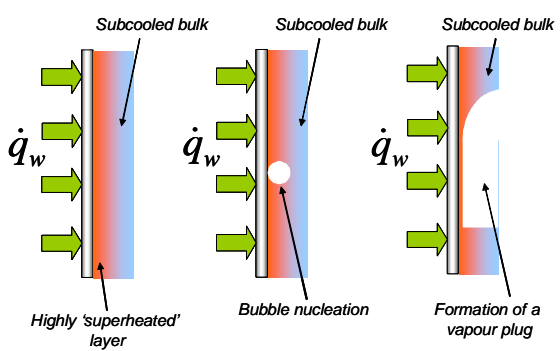

Figure 7. Description of the postulated mechanism of formation of nonequilibrium slug flow (Barbosa and Hewitt, 2004).

A detailed discussion concerning the mechanisms that favour the occurrence of near-zero quality peaks is given elsewhere (Barbosa and Hewitt, 2004). In summary, the four mechanisms are (i) large vapour formation for a given superheat, (ii) low liquid thermal conductivity leading to large differences between the wall temperature and the local saturation temperature, (iii) high subcooling and (iv) low mass transfer resistance to bubble growth. These mechanisms were found to be prevalent in the situations where the phenomenon of heat transfer peaks was identified in the literature. Section 4 will review the mechanistic model for nonequilibrium slug flow that predicts the heat transfer peaks in the near-zero quality region.

Heat Transfer Deterioration at High Qualities: Binary and Multicomponent Mixtures

The second case of departure from the classical behaviour of convective boiling heat transfer is the deterioration of heat transfer coefficient with increasing quality at (high) qualities typical of annular flow. The heat transfer coefficient behaviour as a function of quality is shown in Figure 8 (Kandlbinder, 1997). Similar behaviour was observed by many investigators for a number of binary and multicomponent mixtures in both vertical (Celata et al., 1994; Shatto, 1998) and horizontal systems (Wettermann and Steiner, 2000). An extensive literature review was carried out by Barbosa (2001).

In binary and multicomponent evaporating systems, the difference in volatility between the components gives rise to axial gradients of concentration (and hence of saturation temperature) in both liquid and vapour streams due to the preferential evaporation of the more volatile component(s) even when local component equilibrium occurs. Figure 9, adapted from Thome and Shock
(1984), illustrates the axial distributions of saturation and wall temperature for a mixture and for a single component undergoing phase change in a tube. As quality increases, the liquid phase becomes richer in the less volatile component and the fluid saturation temperature increases (in many cases, overcoming the decrease associated with the negative axial pressure gradient).

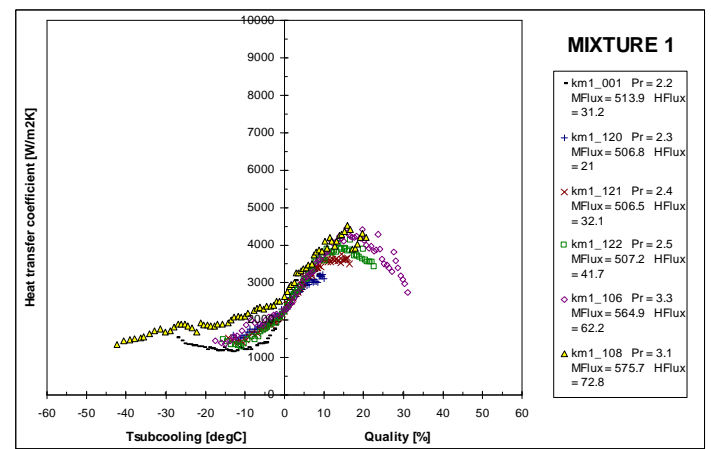

Figure 8. Heat transfer coefficient as a function of the equilibrium quality (saturated region) and of subcooling (subcooled region) in flow boiling of $70 \%$ n-pentane, $30 \%$ iso-octane (molar basis) (Kandlbinder, 1997).

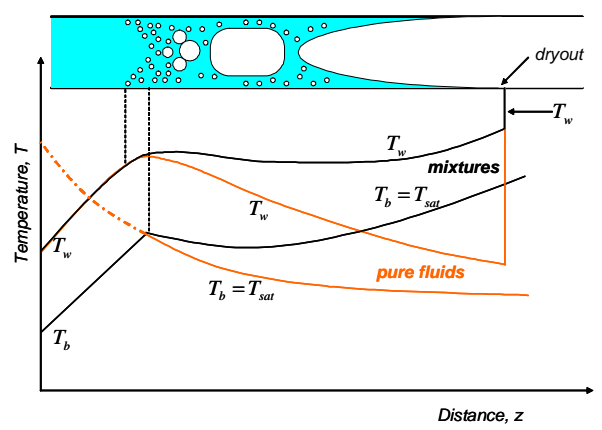

Figure 9. Temperature profiles and boiling regimes for convective evaporation (Thome and Shock, 1984).

In the annular flow regime, without bubble nucleation at the wall, the heat transfer coefficient decrease associated with mixture effects takes place in different ways depending on the form of heating imposed to the surface (Wadekar, 1990). In the present context, mixture effects are defined as the build-up of concentration gradients adjacent to the vapour-liquid interface resulting from the preferential evaporation of the more volatile component(s). This decreases the interfacial concentration of the lighter component, $\tilde{x}_{I}$, to a value lower than the bulk liquid phase concentration, $\tilde{x}_{b}$. For simplicity, ideal cases in which no droplet interchange (entrainment) exists are depicted in Figures 10.a and 10.b. These figures exhibit temperature profiles across the liquid film for prescribed wall temperature and heat flux boundary conditions, respectively. In both cases, profiles with and without mixture effects are shown.

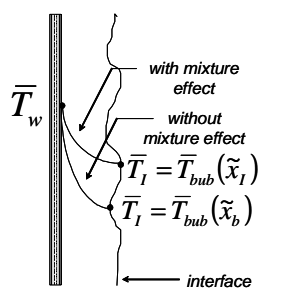

(a)

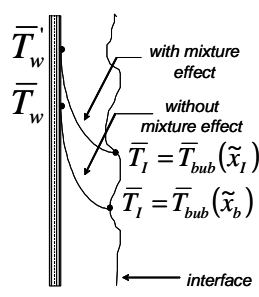

(b)
Figure 10. Illustration of liquid phase temperature profiles; (a) wall temperature controlled case, (b) heat flux controlled case (Wadekar, 1990). $\sim$ denotes mole fraction. 
In the wall temperature controlled case (Figure 10.a), the decrease in the heat transfer coefficient calculated according to Eq. (1) is due to the reduction in the temperature driving force is from $\bar{T}_{w}-\bar{T}_{b u b}\left(\tilde{x}_{b}\right)$ to $\bar{T}_{w}-\bar{T}_{b u b}\left(\tilde{x}_{I}\right)$. In the heat flux controlled case, the rise in the interface temperature does not change the temperature driving force. Rather, this potential must remain unchanged so that the product of the local (film) heat transfer coefficient and the temperature difference is equal to the applied heat flux ${ }^{2}$. The increase in wall temperature from $\bar{T}_{w}$ to $\bar{T}_{w}^{\prime}$ is illustrated in Figure 10.b.

So what causes the reduction of the heat transfer coefficient observed so systematically in the literature for the constant heat flux case? The answer is practicality. For engineering design calculations, it is more convenient to define $\bar{\alpha}$ in terms of $\bar{T}_{w}^{\prime}-\bar{T}_{b u b}\left(\tilde{x}_{b}\right)$ than $\bar{T}_{w}^{\prime}-\bar{T}_{b u b}\left(\tilde{x}_{I}\right)$, where $\bar{T}_{w}^{\prime}$ is generally determined experimentally. Because $\bar{T}_{b u b}\left(\tilde{x}_{b}\right)$ is lower than $\bar{T}_{b u b}\left(\tilde{x}_{I}\right)$, the ratio of the wall heat flux to the design based wall superheat is also lower. It is therefore expected that conventional prediction methods that do not take these effects into account will overestimate the experimental heat transfer coefficient.

As will be shown in Section 5, in order to properly quantify $\bar{T}_{w}^{\prime}$ and $\bar{T}_{b u b}\left(\tilde{x}_{b}\right)$ in the annular flow regime and consequently predict the heat transfer coefficient under forced convective boiling, two mechanisms must be accounted for, namely,

a. Mass transfer resistance as a result of component(s) preferential evaporation and formation of concentration gradients adjacent to phase interface(s) in both phases;

b. A hydrodynamic non-equilibrium resulting from the difference in average concentration between the liquid film and the liquid entrained as droplets in the gas core.

Item $\mathrm{b}$ above is a direct consequence of the processes of droplet entrainment and deposition; vigorous mass exchange phenomena which disrupt the hydrodynamic equilibrium of annular flow. Amongst other effects, these phenomena are known to exert a large influence on important flow parameters like pressure drop (Hewitt and Hall-Taylor, 1970). Nevertheless, the significance of droplet interchange on forced convective boiling of mixtures seems to have been overlooked in previous studies and the correct prediction of this mechanism may hold the key to understanding the deterioration associated with the heat transfer coefficient at high qualities (Barbosa and Hewitt, 2001a, 2001b; Barbosa et al., 2002a, 2002b).

Figure 11 depicts an interpretation of the physics of the mixture vaporization problem. In design calculations, the two-phase flow pattern is usually ignored and it is implicitly assumed that the whole of the liquid flow is available for evaporation (Figure 11.b). Usually, a flash calculation is used to determine the amount of liquid which has evaporated for a given wall heat flux and the saturation (bubble point) temperature of the mixture. The preferential evaporation of the more volatile component gives rise to axial gradients of saturation temperature and of mean concentration in both phases.

In a real situation, however, where the annular flow pattern is the dominant configuration, not all of the liquid is present as a film coating the inner wall of the pipe. Rather, droplets are generated from the crests of disturbance waves which travel along the liquid film and these droplets become entrained in the vapour core (Figure 11.a). The droplets travel at approximately the same velocity as the

2 It is implicitly assumed that the liquid film heat transfer coefficient is independent of mixture effects. The validity ofsuch a hypothesis was discussed by Shock (1976). vapour. All along the channel, droplets are being exchanged between the film and the core by entrainment and deposition. However, this exchange is not rapid enough to maintain equality of composition between the droplets and the film. Bearing in mind that droplet evaporation may be negligible when compared to that of the liquid film (the temperature driving force in the liquid film is much higher), one can argue that in the actual situation not all of the liquid phase will be available for evaporation at a given distance along the pipe. This hydrodynamic effect breaks down the thermodynamic equilibrium relationship existing between quality and mixture saturation temperature.

For the sake of clarity, let us consider first the simplified situation in which a certain amount of liquid is entrained as droplets at the onset of annular flow and in which no further entrainment or deposition occurs downstream of this point. In this case, the initial film flow rate (amount of liquid initially available for evaporation) is equal to the total liquid flow rate less the initial entrained droplet flow rate. Even in this ideal situation where the entrained liquid flow is disregarded in the thermodynamic calculation, vapour-liquid equilibrium still demands that a fixed amount of liquid must be lost by evaporation for a given wall heat flux and, at the point of film depletion ('dryout'), the film (saturation) temperature must be equal to the dew point temperature at the overall composition. Since the film flow rate is less than the total liquid flow rate, then (a) 'dryout' will occur at a shorter distance along the channel than it would if all the liquid were in the film, and (b) the film saturation temperature at a given position will be higher than the saturation temperature calculated for a case in which all the liquid flow is considered in the thermodynamic calculations.

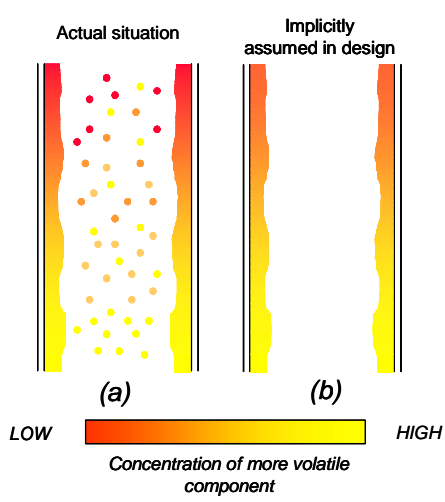

Figure 11. Liquid phase distribution in annular flow of binary and multicomponent mixtures.

Let us consider now the real situation where there is droplet interchange between the liquid film and the vapour core. If droplet evaporation is ignored, then it is natural to suggest that the droplets will retain a concentration equal to that of the liquid film at the point at which they were created (entrained). As an axial gradient of concentration is established in the liquid film due to the preferential evaporation of the more volatile component(s), droplets generated at distinct (axial) positions will have distinct concentrations. Thus, at a particular position, a spectrum of concentration is found in the population of depositing droplets, these droplets having arisen from a variety of positions upstream. When calculating the rate of droplet deposition at a certain distance, one must take into account two important facts, (i) the difference in concentration between groups of droplets, and (ii) the liquid film at that distance is richer in the less volatile component than any depositing droplet. This would tend to smooth the difference between distributions of film concentration (and of liquid film temperature) obtained using the 
simplified 'no interchange' approach for each initial entrained fraction.

In the forced convective region (absence of nucleate boiling), the liquid film heat transfer coefficient is primarily a function of local turbulence and of physical properties. In general, however, the temperature change in the liquid film is dominated by that occurring in the region near the wall where the flow is laminar and turbulence is suppressed. Between this near-wall zone and the interface, the temperature changes little due to the mixing caused by turbulence. This same mixing process in the film leads to a situation where the component concentrations in the liquid film are relatively constant and the interface concentration is close to the mean (fully mixed) concentration in the liquid film. This result was demonstrated quantitatively by Shock (1976), who showed that for any mixture, irrespective of the width of its boiling range, the effect of mass transfer in the liquid film is small enough to be ignored; that is, the interface concentration is close to that of the fully mixed film.

Shock (1976) also investigated the influence of mass transfer in the vapour core. He found that the effects were more significant than those for the liquid film (though still small). The vapour created by evaporation at the interface has to be transported through a laminarlike layer in the vapour adjacent to the interface. This transport process is achieved by a flow normal to the interface coupled with diffusive mass transfer, the latter depending on the concentration gradient of the components. In the work described in this lecture, these mass transfer processes have been considered in detail. It transpires that their effect is small compared to the drop/film concentration difference effect mentioned above, though they could become significant in some circumstances.

\section{Thermodynamic Non-Equilibrium Slug Flow}

\section{Governing Equations}

The model is based on a succession of slug units consisting of a Taylor bubble (formed as a result of the abrupt vapour growth in the subcooled region) surrounded by a falling liquid film and a liquid slug (Figure 12). Due to the formation of the vapour plugs in the subcooled bulk region, it is postulated that the liquid slugs are initially subcooled. Additional simplifications are proposed: (i) a substantial portion of the energy associated with the high temperatures in the near-wall region is consumed in the process of generation of the Taylor bubble and therefore the falling film is assumed saturated, (ii) phase change in the liquid slug and slug body gas hold-up are negligible, (iii) the thickness of the liquid film surrounding the Taylor bubble is small compared with the pipe diameter, (iv) the mass of the liquid film is small compared with that of the slug, (v) phase densities are constant within the slug unit, and (vi) the rate of change of the Taylor bubble length with time is small compared with the ascension velocity of the Taylor bubble. Energy balances over the slug unit and the over the liquid slug give (Barbosa and Hewitt, 2004),

$$
\begin{gathered}
\frac{d L_{B}}{d z}=\frac{1}{\rho_{G} \Delta h_{v}}\left[\frac{4 \dot{q}_{w}\left(L_{B}+L_{S}\right)}{d_{T} V_{G B}}-\rho_{L} c_{p L} L_{S} \frac{d \bar{T}_{S}}{d z}\right], \\
\frac{d L_{S}}{d z}=\frac{1}{\Delta h_{v}}\left[c_{p L} L_{S} \frac{d \bar{T}_{S}}{d z}-\frac{4 \dot{q}_{w}\left(L_{B}+L_{S}\right)}{\rho_{L} d_{T} V_{G B}}\right], \\
\frac{d \bar{T}_{S}}{d z}=\frac{4}{d_{T}} \frac{\dot{q}_{w}}{\rho_{L} c_{p L} V_{L S}}-\frac{\rho_{G}}{\rho_{L}} \frac{1}{L_{S}} \frac{d L_{B}}{d z}\left(T_{s a t}-\bar{T}_{S}\right),
\end{gathered}
$$

where $L_{B}$ and $L_{S}$ are the lengths of the Taylor bubble and of the liquid slug regions, $\bar{T}_{S}$ is the average temperature of the liquid slug, $V_{G B}$ and $V_{L S}$ are the velocities of the centre of mass of the Taylor bubble and of the liquid slug, respectively.

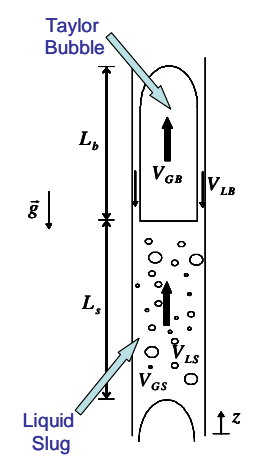

Figure 12. Geometry of a slug unit.

To close the model, the above equations are combined with mass conservation relationships borrowed from steady-state slug flow models (Fernandes et al., 1983; Orell and Rembrand, 1986; Sylvester, 1987; De Cachard and Delhaye, 1996).

$$
\begin{gathered}
U_{G S}=\beta \varepsilon_{B} V_{G B}, \\
\varepsilon_{B} V_{G B}+\left(1-\varepsilon_{B}\right) V_{L B}=U_{M}, \\
V_{L S}=U_{M}=U_{G S}+U_{L S}=G\left[\left(1-x_{G}\right) / \rho_{L}+x_{G} / \rho_{G}\right], \\
V_{G B}=1.2 U_{M}+V_{0},
\end{gathered}
$$

where $U_{M}$ is the mixture velocity. The rise velocity of a Taylor bubble in a quiescent liquid, $V_{0}$, and the falling film velocity, $V_{L B}$, are obtained through empirical relationships provided by Wallis (1969).

The model equations are solved so that at each step $\Delta z$, a value of $\beta$ (defined as the ratio of the Taylor bubble length to the length of the slug unit) is calculated together with the real quality, $x_{G}$, and the remaining slug flow parameters. It is postulated that the onset of slug flow is associated with the point at which vapour is initially formed and the correlation of Saha and Zuber (1974) for the Point of Net Vapour Generation (NVG) is used to calculate the distance from the liquid inlet up to the point of initiation of slug flow. The model of Saha and Zuber also provides the liquid slug temperature at the onset of slug flow. A thorough discussion concerning the determination of the initial conditions for the Taylor bubble and liquid slug lengths is given elsewhere (Barbosa and Hewitt, 2004).

\section{Heat Transfer}

In slug flow, the local time averaged wall temperature to be used in Eq. (1) is defined as (Barnea and Yacoub, 1983),

$$
\begin{aligned}
& \bar{T}_{w}=\frac{1}{t_{s p}} \int_{0}^{t_{s p}} T_{w} d t=\frac{1}{t_{s p}}\left[\int_{0}^{t_{s f}} T_{w} d t+\int_{t_{s f}}^{t_{s f}+t_{s s}} T_{w} d t\right]= \\
& \frac{1}{t_{s p}}\left(t_{s f} \bar{T}_{w, f}+t_{s s} \bar{T}_{w, S}\right)=\beta \bar{T}_{w, f}+(1-\beta) \bar{T}_{w, S}
\end{aligned}
$$


In the liquid slug and in the Taylor bubble regions, superposition models for forced convective boiling (Chen, 1966) were used to determine the local time-averaged wall temperatures. These are as follows (note that slug body subcooling is assumed),

$$
\begin{gathered}
\bar{T}_{w, S}=\frac{\dot{q}_{w}+\bar{\alpha}_{f c, S} \bar{T}_{S}+\bar{\alpha}_{n b, S} T_{s a t}}{\bar{\alpha}_{f c, S}+\bar{\alpha}_{n b, S}}, \\
\bar{T}_{w, f}=T_{s a t}+\frac{\dot{q}_{w}}{\bar{\alpha}_{f c, f}+\bar{\alpha}_{n b, f}} .
\end{gathered}
$$

The forced convective terms of the heat transfer coefficients in the falling film and slug regions, $\bar{\alpha}_{f c, f}$ and $\bar{\alpha}_{f c, S}$ were calculated using the Chun and Seban (1971) correlation and the Chen (1966) model modified according to Butterworth and Shock (1982) to deal with subcooling effects. The nucleate boiling terms $\bar{\alpha}_{n b, f}$ and $\bar{\alpha}_{n b, S}$ were calculated according to the Chen (1996) model.

\section{Results}

The experimental heat transfer coefficient behaviour, together with the difference between the slug temperature and the equilibrium bulk temperature is shown in Figure 13 for a typical npentane boiling run. In this case, the temperature difference increases from zero up to $3 \mathrm{oC}$ at the point where $\bar{T}_{b}=T_{\text {sat }}$ and then starts to decrease. $\bar{T}_{b}$ is the local equilibrium bulk temperature and $T_{\text {sat }}$ is the local saturation temperature. Two vertical lines in Figure 13 define the portion of the flow in which the slug flow pattern prevails according to the model. The line upstream of the peak represents the NVG Point (Saha and Zuber, 1974) and the line downstream of the peak marks the transition to churn flow according to the model of Jayanti and Hewitt (1992). In this figure, a coincidence is observed in the locations of the regions of maxima in the $\bar{T}_{b}-\bar{T}_{S}$ and in the heat transfer coefficient profiles. This fact was observed consistently in the simulations (as can be seen from two examples in Figures 14 and 15) and is crucial to understanding the model's ability to predict the heat transfer coefficient peaks in the near-zero quality region.

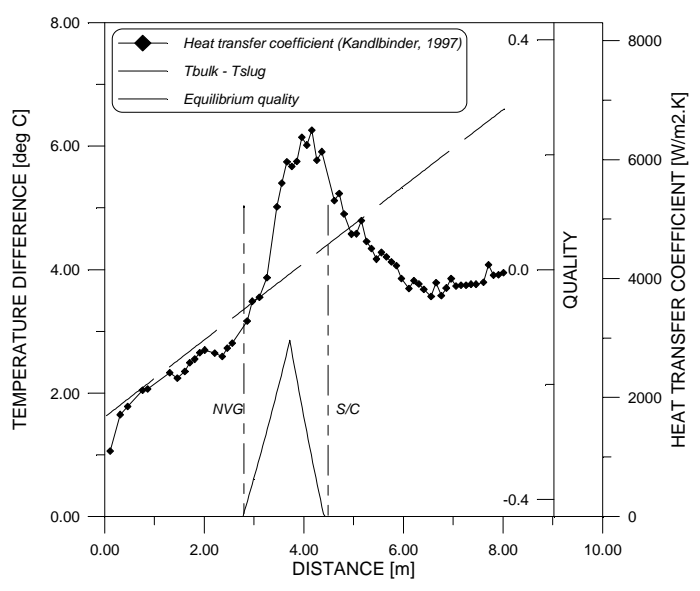

Figure 13. Slug to equilibrium bulk temperature difference as a function of distance. N-pentane, inlet pressure: 4.9 bar, total mass flux: $376.0 \mathrm{~kg} / \mathrm{m}^{2} \mathrm{~s}$, distance. N-pentane, inlet pressure: 4.9 bar, total mas
wal heat flux $50.0 \mathrm{~kW} / \mathrm{m}^{2}$, inlet temperature: $60.7 \mathrm{oC}$.

A bubble that nucleates adjacent to the wall may grow sufficiently to form a vapour plug and induce an early transition to churn flow in the subcooled bulk region. As this bubble continues to grow, it accelerates the liquid slug ahead of it, thus reducing the residence time of the liquid slug in the pipe. With their residence times reduced, the liquid slugs will remain subcooled at greater distances along the pipe where, according to the thermodynamic equilibrium hypothesis, they should be saturated. As a result, at a given distance, the real quality (and consequently the heat transfer coefficient, because of a lower time-averaged wall temperature) will be higher than that calculated assuming thermodynamic equilibrium.

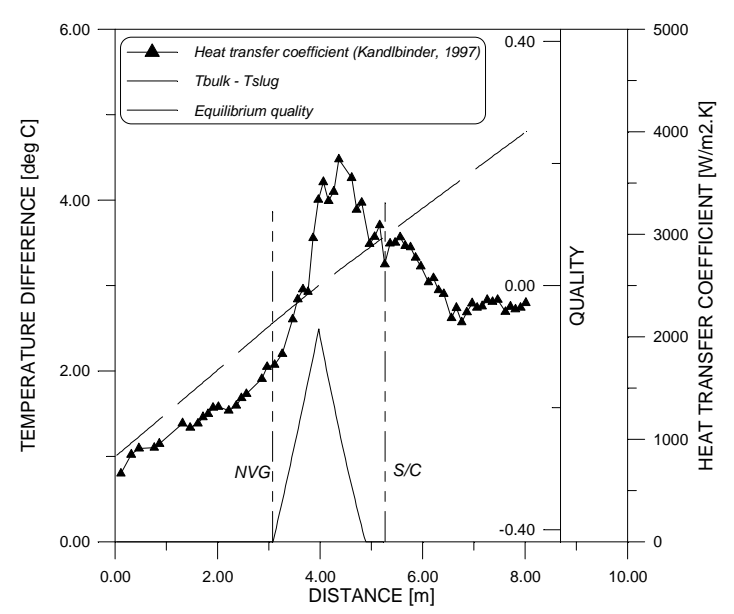

Figure 14. Slug to equilibrium bulk temperature difference as a function of distance. Iso-octane, inlet pressure: 3.1 bar, total mass flux: $200.8 \mathrm{~kg} / \mathrm{m}^{2} \mathrm{~s}$, wal heat flux $19.5 \mathrm{~kW} / \mathrm{m}^{2}$, inlet temperature: $117.4^{\circ} \mathrm{C}$.

As can be seen from the slug temperature profiles shown in Figures 16 and 17, since the liquid slug velocity increases continuously as a result of acceleration of the Taylor bubble, the subcooling reduction is much less pronounced as a function of distance than what would be the case under thermodynamic equilibrium. In addition, Figures 13-15 show that as the transition to churn flow is approached $(\mathrm{S} / \mathrm{C})$ there is a decrease in the heat transfer coefficient to values typical of those normally associated with the classical behaviour (Collier and Thome, 1994; Hewitt, 2000). Since the slug-to-churn flow transition is triggered by the collapse of the slug unit, the resulting homogenization of the phases in the Taylor bubble region and in the liquid slug would eliminate the local subcooling effects responsible for maintaining the local heat transfer enhancement. This phenomenon is most visible in Figures 15 and 17.

The ability of the methodology to predict the local heat transfer coefficient behaviour is illustrated in Figures 18 and 19 for typical n-pentane and iso-octane runs. In both cases, the experimental data trends are well predicted upstream and downstream of the saturation point (marked by "X"). As a result of the calculated peaks in the $\bar{T}_{b}-\bar{T}_{S}$ profiles, the zones of higher calculated heat transfer coefficients also coincide with the experimental ones.

Results given by the Chen (1966) correlation corrected for subcooling effetcs (Butterworth and Shock, 1982) are also shown in Figures 18 and 19. As can be seen, the non-equilibrium slug flow model performs better than the Chen (1966) correlation in both situations. In the equilibrium saturation region (downstream of "X"), the Chen model predicts an increase in the heat transfer coefficient, opposing the trends of the experimental data and of the non-equilibrium model. In summary, as observed by Kandlbinder (1997), the model of Chen (1966), together with other flow boiling correlations (Shah, 1982; Kandlikar, 1990; Steiner \& Taborek, 1992), underestimate considerably the heat transfer coefficient in the near-zero quality region and are unable to predict zones of local 
maxima in the heat transfer coefficient profiles. The general performance of the model over a representative range of the database of Kandlbinder (1997) is presented in Figure 20, where $95 \%$ of the non-equilibrium model data lies in the $+/-18 \%$ relative error band.

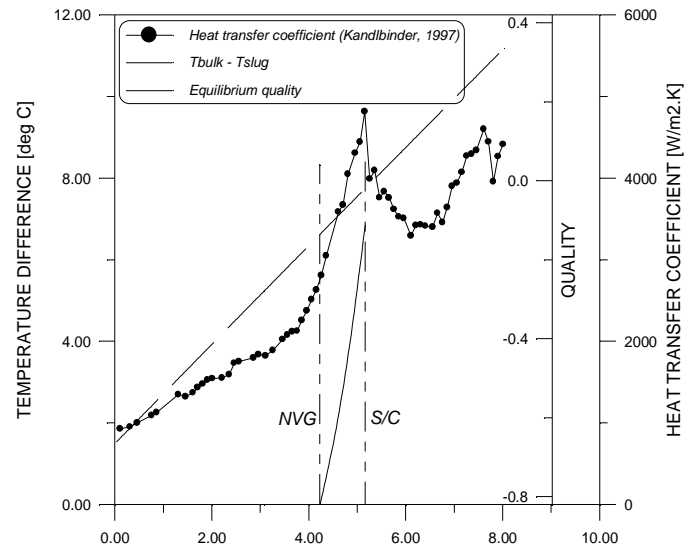

Figure 15. Slug to equilibrium bulk temperature difference as a function of distance. Iso-octane, inlet pressure: 2.2 bar, total mass flux: $296.7 \mathrm{~kg} / \mathrm{m}^{2} \mathrm{~s}$, wal heat flux $60.1 \mathrm{~kW} / \mathrm{m}^{2}$, inlet temperature: $55.3^{\circ} \mathrm{C}$.

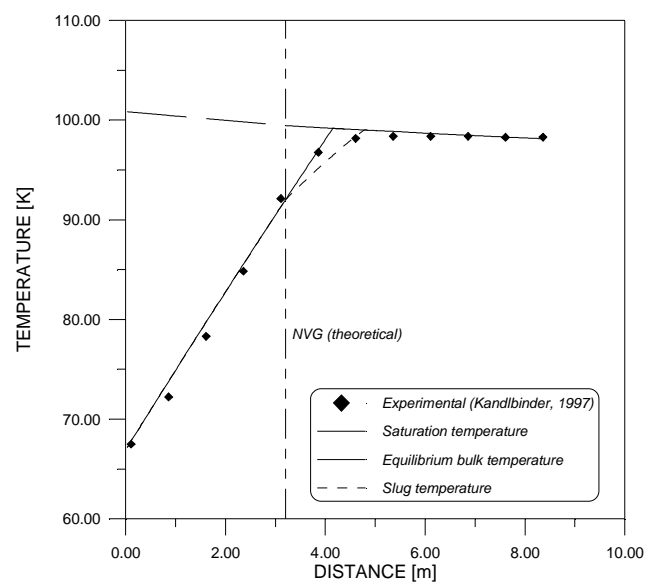

Figure 16. Axial temperature profiles (measured at the centreline Kandlbinder, 1997). N-pentane, inlet pressure: 6.0 bar, mass flux: 377.4 $\mathrm{kg} / \mathrm{m}^{2} \mathrm{~s}$, wall heat flux: $49.9 \mathrm{~kW} / \mathrm{m}^{2}$, inlet temperature: $67.5^{\circ} \mathrm{C}$.

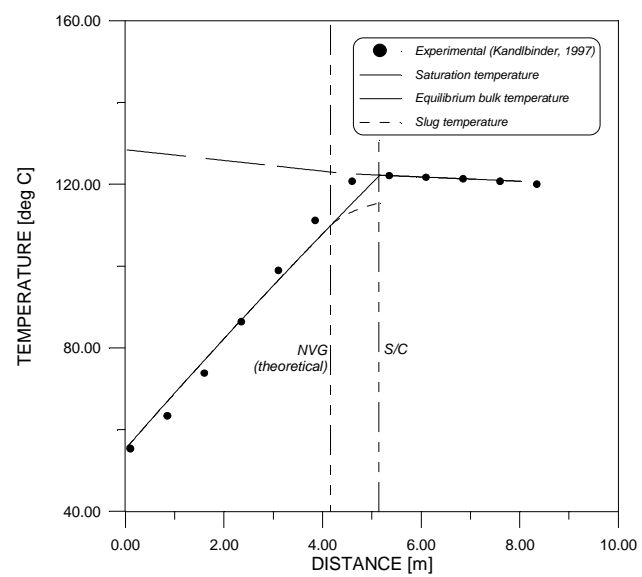

Figure 17. Axial temperature profiles (measured at the centreline Kandlbinder, 1997). Iso-octane, inlet pressure: 2.2 bar, total mass flux: $296.7 \mathrm{~kg} / \mathrm{m}^{2} \mathrm{~s}$, wall heat flux: $60.1 \mathrm{~kW} / \mathrm{m}^{2}$, inlet temperature: $55.3^{\circ} \mathrm{C}$.

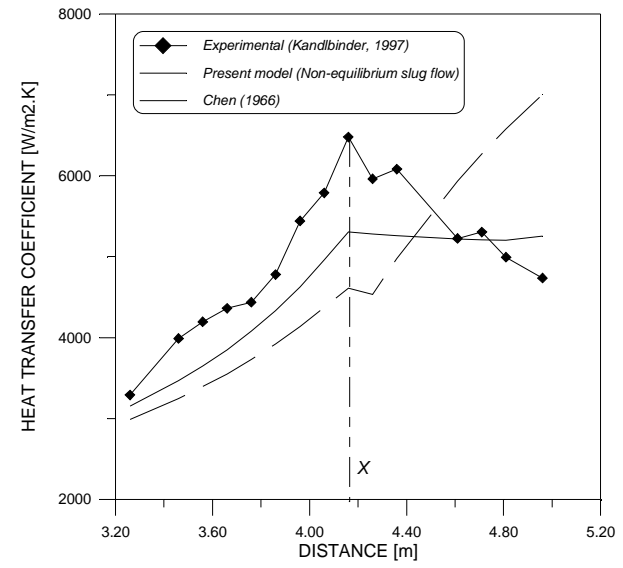

Figure 18. Local heat transfer coefficient prediction. $\mathrm{N}$-pentane, inlet pressure: 6.0 bar, total mass flux: $377.4 \mathrm{~kg} / \mathrm{m}^{2} \mathrm{~s}$, total heat flux: 49.9 $\mathrm{kW} / \mathrm{m}^{2}$, inlet temperature: $67.5^{\circ} \mathrm{C}$.

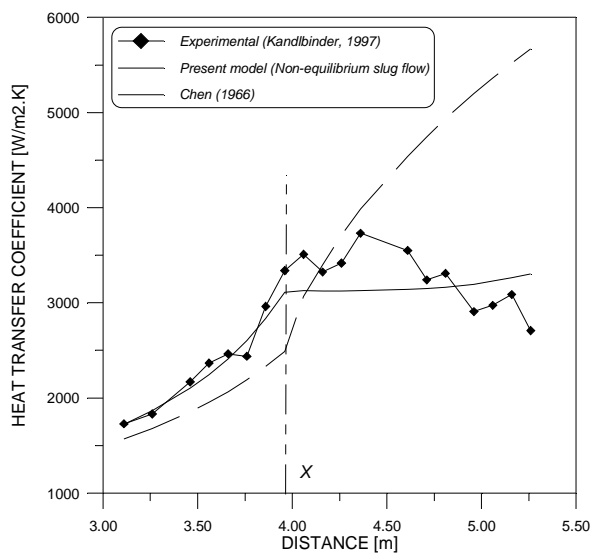

Figure 19. Local heat transfer coefficient prediction. Iso-octane, inle pressure: 3.1 bar, total mass flux: $200.8 \mathrm{~kg} / \mathrm{m}^{2} \mathrm{~s}$, total heat flux: 19.5 $\mathrm{kW} / \mathrm{m}^{2}$, inlet temperature: $117.4^{\circ} \mathrm{C}$.

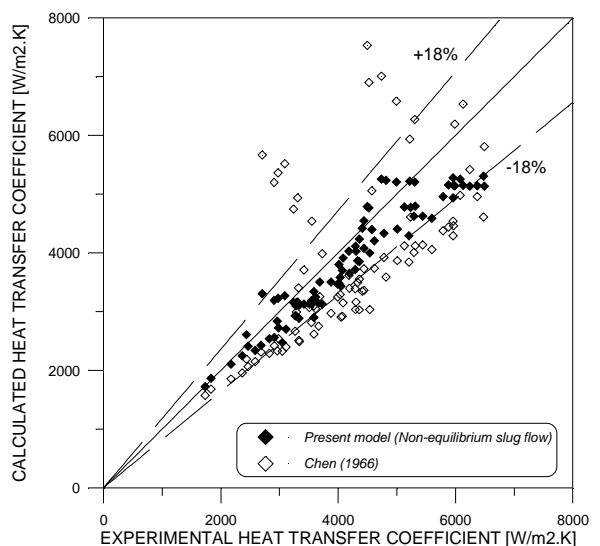

Figure 20. Comparison between experimental and calculated local hea transfer coefficients.

\section{Annular Flow of Binary and Multicomponent Mixtures}

\section{Hydrodynamics}

The physical model is schematically illustrated in Figure 21. The portion of the vertical pipe over which annular flow occurs is divided into $M$ sections, 0 being the section at which the onset of 
annular flow takes place. The mass flow rates per unit crosssectional area, $\dot{m}$, of the three fields, viz., liquid film, $L F$, vapour core, $G C$, and entrained liquid, $L E$, are shown. The initial bulk concentrations (in terms of mass fractions) of the $i^{\text {th }}$ component in the liquid film, entrained droplets and vapour core are $x_{L F, i}^{0}, x_{L E, i}^{0}$ and $y_{G C, i}^{0}$, respectively. An initial value is assumed for the fraction of liquid entrained as droplets at the point of initiation of the annular regime and the concentration of the respective components in this initially entrained liquid is assumed equal (at this point) to that of the liquid film (though differences develop later). The transition to annular flow is determined by the critical velocity criterion for flow reversal due to Wallis (1969).

The number of droplets depositing per unit time per unit area of tube wall at section $\mathrm{m}$ is defined by the cumulative operator as follows,

$$
\left\langle n_{D}^{m}\right\rangle=\sum_{j=0}^{m} n_{D}^{j, m}
$$

where, $n_{D}^{j, m}$ is the number of droplets per unit time per unit area of tube wall that were entrained at a section $\mathrm{j}$ (lower than $\mathrm{m}$ ) and that deposit at section m. Analogously, $n_{E}^{m}$ is defined as the number of droplets per unit time per unit area of tube wall that were entrained at section $\mathrm{m}$. If the entrainment and deposition rates at any point in the channel are known, then $n_{D}^{j, m}$ and $n_{E}^{m}$ are given by,

$$
n_{E}^{m}=\frac{E^{m}}{M_{p c}^{m}}
$$

and,

$$
n_{D}^{j, m}=\frac{D^{j, m}}{M_{p}^{j, m}}
$$

where $E$ and $D$ are rates of droplet entrainment and deposition and $M$ is the mass of a droplet. Subscripts $p$ and $p c$ stand for droplet and droplet at the moment of creation, respectively.

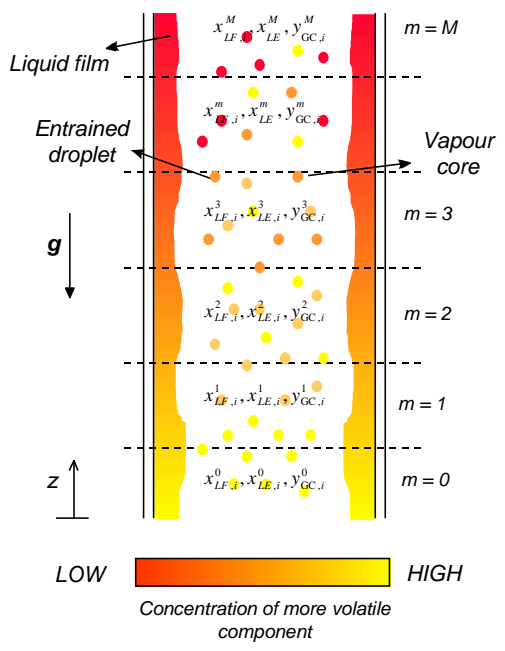

Figure 21. A schematic of the annular flow model.
Droplets were assumed spherical and droplet diameters at creation were calculated through the correlation of Azzopardi et al. (1980). The entrainment and deposition rates, $E^{m}$ and $D^{j, m}$ were determined through a modification of the set of correlations developed by Govan et al. (1988). A more detailed description of the liquid phase mass interchange between the liquid film and the entrained droplets is given in Barbosa and Hewitt (2001a).

The following differential equations are obtained through mass balances over an element of tube of length $d z$ for a mixture of NOC components. Equations (17) to (19) represent overall mass conservation for the liquid film, vapour core and liquid entrained as droplets. Equation (20) is a component mass balance for the liquid film. The effect of deposition of droplets having different concentrations is characterised by the expression in parenthesis in the RHS of Eq. (20).

$$
\begin{gathered}
\frac{d}{d z} \dot{m}_{L F}=\frac{4}{d_{T}}\left(\langle D\rangle-E-\sum_{j=1}^{N O C} \dot{m}_{I, j}\right), \\
\frac{d}{d z} \dot{m}_{G C}=\frac{4}{d_{T}} \sum_{j=1}^{N O C} \dot{m}_{I, j}, \\
\frac{d}{d z} \dot{m}_{L E}=\frac{4}{d_{T}}(E-\langle D\rangle), \\
\frac{d}{d z} x_{L F, i}=\frac{4}{d_{T} \dot{m}_{L F}}\left[\left(\left\langle D x_{L F, i}\right\rangle-\langle D\rangle x_{L F, i}\right)+\sum_{j=1}^{N O C} \dot{m}_{I, j} x_{L F, i}-\dot{m}_{I, i}\right] .
\end{gathered}
$$

$\dot{m}_{I, i}$ is the mass flux of component $\mathrm{i}$ in the evaporating stream, calculated through a model for simultaneous interfacial heat and mass transfer based on a film (or Colburn) method in which the effect of droplet interchange is taken into account in the interfacial heat balance (see Section 5.2). An energy balance over an element of length $d z$ gives,

$\frac{d}{d z} T_{C}=\frac{4}{d_{T} \dot{m}_{C} c_{p C}}\left[\alpha_{G C}^{\cdot}\left(T_{I}-T_{C}\right)+(E-\langle D\rangle)_{p_{L E}}\left(T_{I}-T_{C}\right)\right]$,

where the subscript $C$ represents the homogeneous core properties and $\alpha_{G C}^{\bullet}$ is the finite-flux gas core heat transfer coefficient (Bird et al., 1960). The momentum conservation and additional closure relationships for hydrodynamics were obtained from an annular flow modelling framework (Hawkes, 1996; Barbosa, 2001) in which the triangular relationship between film thickness, film flow rate and interfacial shear stress is invoked together with the relationships for entrainment and deposition rates.

\section{Heat and Mass Transfer}

At each integration step $\Delta z$, an iterative procedure is carried out to determine the interfacial mass fluxes, compositions and temperature. Classically, the film interface condition can be determined by either assuming full or no mixing in the liquid film. For the present geometry and flow regime in the liquid film, the fully mixed liquid determinacy condition seems more appropriate. In this case, the interfacial liquid composition is known a priori (i.e., it is equal to the mean film composition) and a bubble point calculation defines the interfacial state. The solution algorithm for the interphase heat and mass transfer calculation is as follows (Webb, 1982),

1. Known: $x_{L F_{I, i}}\left(x_{L F_{b, i}}\right), y_{b, i}, T_{C}$; 
2. Calculate: $y_{I, i}, T_{I} \rightarrow$ Bubble point temperature subroutine;

3. Guess: $\sum_{j=1}^{N O C} \dot{m}_{I, j}$;

4. Calculate: $\dot{m}_{I, j} / \sum_{j=1}^{N O C} \dot{m}_{I, j} \rightarrow$ Eq. (26);

5. Calculate: $\dot{q}_{\mathrm{GC}} \rightarrow E q$. (22);

6. Compare: If $\dot{q}_{\mathrm{GC}} \neq \dot{q}_{W}-\dot{q}_{E D}$, update $\sum_{j=1}^{N O C} \dot{m}_{I, j}$ and return to step 4.

The relationships utilized in the interfacial heat and mass iterative balances are summarized in Table 1 . The elements of the diagonal matrix of diffusion coefficients, $[\Delta]$, are determined through an Effective Diffusivity approach or through and Interactive Method (Taylor and Krishna, 1993). In either case, Maxwell-Stefan diffusion coefficients for the gas phase were calculated assuming ideal gas behaviour using the correlation of Fuller et al. (1964). For additional details concerning the interphase heat and mass transfer formulation, see Barbosa et al. (2002a).

Step 6 of the iterative algorithm assumes $\dot{q}_{\mathrm{GC}}=\dot{q}_{w}-\dot{q}_{E D}$, where $\dot{q}_{E D}=(E-\langle D\rangle) c_{p L E}\left(T_{I}-T_{C}\right)$ is the energy released/absorbed by the entrained droplets due to entrainment and deposition. Finally, the time-averaged wall temperature, $\bar{T}_{W}$, is given by $\bar{T}_{W}=T_{I}+\dot{q}_{W} / \alpha_{L F}$, where $\alpha_{L F}$ is the heat transfer coefficient for the liquid film calculated using the correlation of Chen (1966) with the (small) nucleate boiling component corrected for mixture effects as suggested by Palen (1992).

Table 1. Summary of interfacial balance equations.

\begin{tabular}{|lll|}
\hline \multicolumn{1}{|c|}{ Heat Transfer } & \multicolumn{1}{c|}{ Mass Transfer } \\
\hline$\dot{q}_{\mathrm{GC}}=\sum_{j=1}^{N O C} \dot{m}_{I, j} \Delta \mathrm{h}_{\mathrm{v}, \mathrm{j}}+\alpha_{\mathrm{GC}}^{\cdot} e^{\phi_{T}}\left(T_{I}-T_{C}\right)$ & $(22)$ & $\dot{m}_{I, i}=y_{I, i} \sum_{j=1}^{N O C} \dot{m}_{I, j}+\rho_{\mathrm{GC}} B_{\mathrm{G}, \mathrm{i}}^{\circ}\left(y_{I, i}-y_{b, i}\right)$ \\
\hline$\alpha_{\mathrm{GC}}^{\cdot}=\frac{\alpha_{\mathrm{GC}} \phi_{T}}{e^{\phi_{T}}-1}$ & $(23)$ & {$\left[B_{\mathrm{G}}^{\bullet}\right]=\left[B_{\mathrm{G}}[\Phi][\exp [\Phi]-[I]]^{-1}\right.$} \\
\hline$\phi_{T}=\frac{1}{\alpha_{\mathrm{GC}}} \sum_{j=1}^{N O C} \dot{m}_{I, j} c_{p \mathrm{GC}, \mathrm{j}}$ & $(24)$ & {$[\Phi]=\frac{1}{\rho_{\mathrm{GC}}} \sum_{j=1}^{N O C} \dot{m}_{I, j}\left[B_{\mathrm{G}}\right]^{-1}$} \\
\hline$\frac{\alpha_{\mathrm{GC}} d_{T}}{\lambda_{\mathrm{GC}}}=0.023 \operatorname{Re}_{\mathrm{GC}}^{0.8} \operatorname{Pr}_{\mathrm{GC}}^{0.4}$ & $(25)$ & {$\left[B_{\mathrm{G}}\right] d_{T}[\Delta]^{-1}=0.023 \operatorname{Re}_{\mathrm{GC}}^{0.8}\left(\frac{\rho_{\mathrm{GC}}}{\eta_{\mathrm{GC}}}[\Delta]^{-1}\right)^{0.4}$} \\
\hline
\end{tabular}

In Table $\left.1, \mid B_{G}^{\bullet}\right\rfloor$ is the matrix of finite-flux mass transfer coefficients and $\phi_{T}$ and $[\Phi]$ are the finite-flux correction factor for heat transfer and the finite-flux correction matrix for mass transfer (Bird et al., 1960).

\section{The Effect of Initial Entrained Fraction}

In single component systems, the modelling work of Govan (1990) showed that the behaviour of thermal parameters such as the local heat transfer coefficient and the critical heat flux are affected only slightly by the fraction of the total liquid flow entrained as droplets at the onset of annular flow. On the other hand, it has been shown that for annular flow of binary (Barbosa and Hewitt, 2001a, 2001b) and of ternary mixtures (Barbosa and Hewitt, 1999; Barbosa et al., 2002a) significant discrepancies may develop between profiles of local heat transfer coefficient calculated using different (hypothetical, but within a realistic range; say, from $0 \%$ to $40 \%$ ) initial entrained liquid fractions. These discrepancies arise as the initial entrained fraction affects the downstream distribution of the components between the drops and the liquid film, giving rise to the hydrodynamic non-equilibrium phenomenon described in Section 3.1. It is, therefore, essential that appropriate boundary conditions for the initial entrained fraction are provided in order to solve the heat and mass transfer in flow boiling of mixtures at high qualities.

An empirical correlation was developed (Barbosa et al., 2002c) to calculate the fraction of the total liquid flow entrained as droplets at the region of transition between the churn flow and the annular flow regimes. Measurements of local gas and entrained liquid mass fluxes were carried out using an isokinetic probe system. Amongst other findings, it was observed that in the fully co-current annular flow region local droplet concentration is virtually constant within the gas core. In contrast, the churn flow regime exhibits rather sharp radial gradients of concentration which gradually disappear with increasing gas velocity. The correlation is as follows,

$$
e_{O A} \%=\left.\frac{\dot{m}_{L E}}{\dot{m}_{L E}+\dot{m}_{L F}}\right|_{O A} \times 100=0.95+324.55 \sqrt{\frac{\rho_{L} \dot{m}_{L}}{\rho_{G} \dot{m}_{G}}} d_{T}^{2} .
$$

Equation 30 was used to compute the entrained fraction in adiabatic air-water systems and was also incorporated into the binary and multicomponent annular flow boiling calculation framework (Barbosa et al., 2002b). As will be seen in Section 5.4, a comparison of local wall temperature profiles and local and average heat transfer coefficients for flow boiling of binary and ternary hydrocarbon mixtures (Kandlbinder, 1997) reveals an encouraging agreement between the theory and the experimental data.

\section{Results}

The model predictions were extensively compared with the experimental database of Kandlbinder (1997) for forced convective boiling experiments of pure hydrocarbons (n-pentane, $n$-hexane and iso-octane) and their mixtures in an $8.68 \mathrm{~m}$ long, vertical 321 stainless steel tube test section. The inner and outer diameters were 25.4 and $38.0 \mathrm{~mm}$, respectively. Along the test section, bulk fluid (centreline) and wall temperatures were measured.

Temperature profiles are illustrated in Figures 22 to 24 for typical conditions. In these figures, the fraction of the total liquid flow entrained as droplets at the onset of annular flow was varied from $0 \%$ to $40 \%$. As can be seen, due to concentration nonequilibrium between the entrained liquid and the liquid film, differences between the core, interface and wall temperatures (as a function of initial entrainment) develop as a function of axial distance. In general, agreement between the calculated and experimental results is very encouraging. 


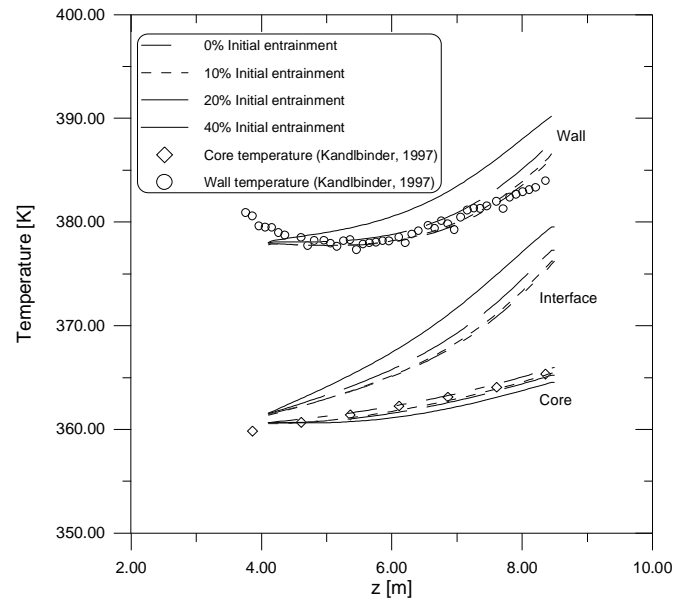

Figure 22. Local wall, interface and core (centerline) temperature prediction as a function of initial entrained fraction. Mixture $0.7 / 0.3$ pentane/iso-octane (mole fraction), inlet pressure: 2.3 bar, Wall heat flux: $49.8 \mathrm{~kW} \mathrm{m-2}$, total mass flux: $292.8 \mathrm{~kg} \mathrm{~m}-2 \mathrm{~s}-1$.

Figures 25.a and 25.b illustrate the differences in bulk concentration (mass fraction) of the more volatile component in a binary mixture as a function of distance for different initial entrained fractions. An opposite effect is observed in the behaviour of concentration in the two streams as a result of the combination of preferential evaporation and initial availability of liquid for evaporation in the liquid film (Barbosa and Hewitt, 2001a).

In the ternary mixture case (Figure 26), differences between liquid film and droplets bulk concentrations (mass fraction) are shown for the lightest (n-pentane) and heaviest (iso-octane) components. For each component, the differences grow larger as a function of distance, with the droplets becoming richer in the more volatile component (Barbosa et al., 2002a).

Local heat transfer coefficient predictions are illustrated in Figures 27-29. Again, the initial entrained fraction is varied from $0 \%$ to $40 \%$. However, curves are also shown for initial entrained fractions calculated according to Eq. (30) (Barbosa et al., 2002b). The agreement with the experimental data is satisfactory, thus providing an indication of the range of initial entrained fractions in such flows.

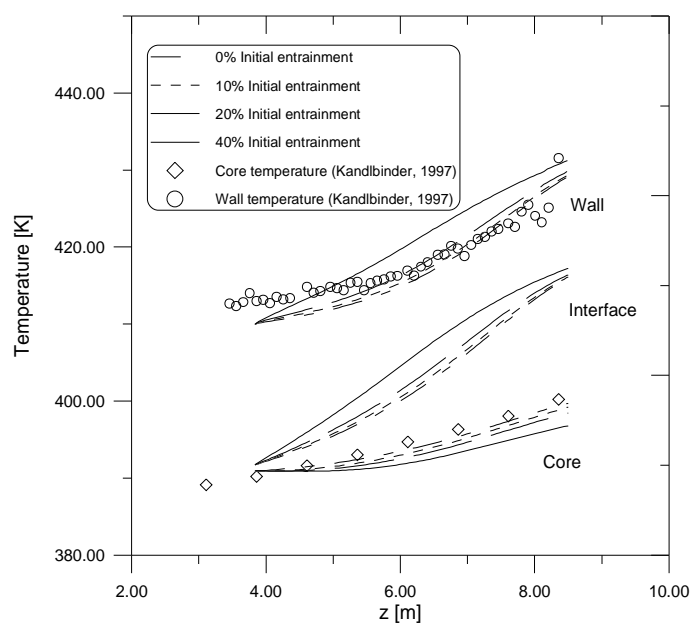

Figure 23. Local wall, interface and core (centerline) temperature prediction as a function of initial entrained fraction. Mixture $0.7 / 0.3$ pentane/iso-octane (mole fraction), inlet pressure: $\mathbf{3 . 2}$ bar, wall heat flux: $49.3 \mathrm{~kW} \mathrm{m-2}$, total mass flux: $305.0 \mathrm{~kg} \mathrm{~m}-2 \mathrm{~s}-1$.

J. of the Braz. Soc. of Mech. Sci. \& Eng.

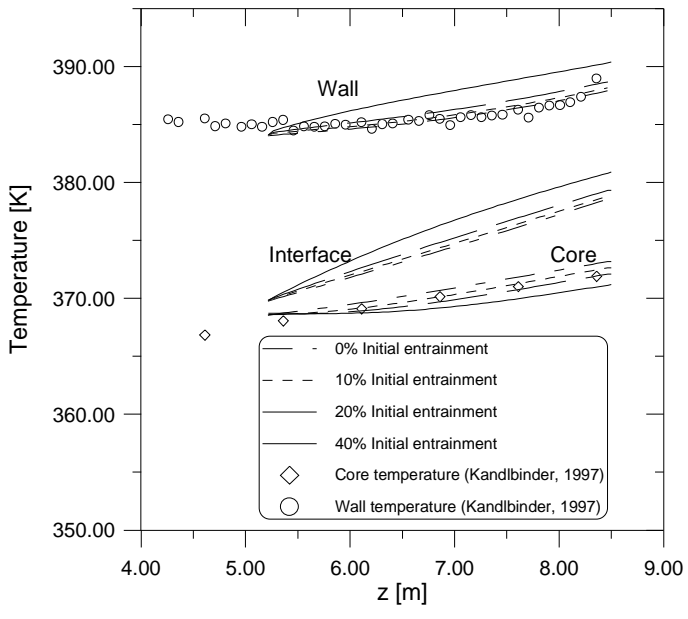

Figure 24. Local wall, interface and core (centerline) temperature prediction as a function of initial entrained fraction. Mixture $0.31 / 0.22 / 0.47$ pentane/hexane/iso-octane (mole fraction), inlet pressure: $3.10 \mathrm{bar}$, Wall heat flux: $49.5 \mathrm{~kW} \mathrm{m-2}$, total mass flux: $296.0 \mathrm{~kg} \mathrm{~m}-2 \mathrm{~s}-1$.
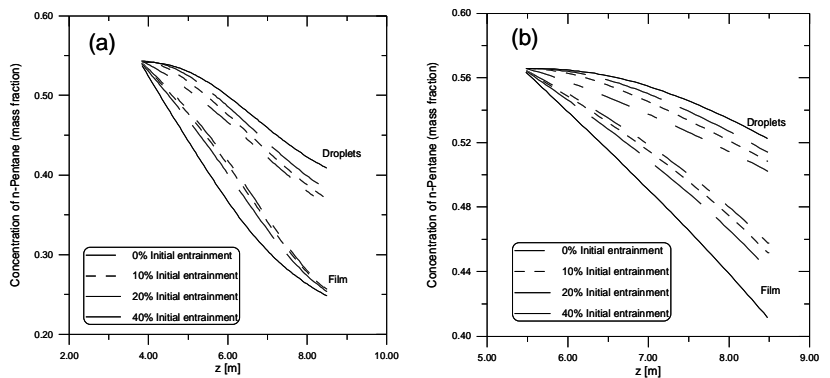

Figure 25. Profiles of mean concentration of n-pentane (mass fraction) in the liquid film and in the liquid droplets. (a) Mixture $0.7 / 0.3$ pentane/isooctane (mole fraction), inlet pressure: 2.3 bar, wall heat flux: $49.8 \mathrm{~kW} \mathrm{m-2}$, total mass flux: $292.8 \mathrm{~kg} \mathrm{~m}-2 \mathrm{~s}-1$. (b) Mixture $0.7 / 0.3$ pentane/iso-octane (mole fraction), inlet pressure: 3.2 bar, wall heat flux: $49.3 \mathrm{~kW} \mathrm{m-2,} \mathrm{total}$ mass flux: $305.0 \mathrm{~kg} \mathrm{~m}-2 \mathrm{~s}-1$.

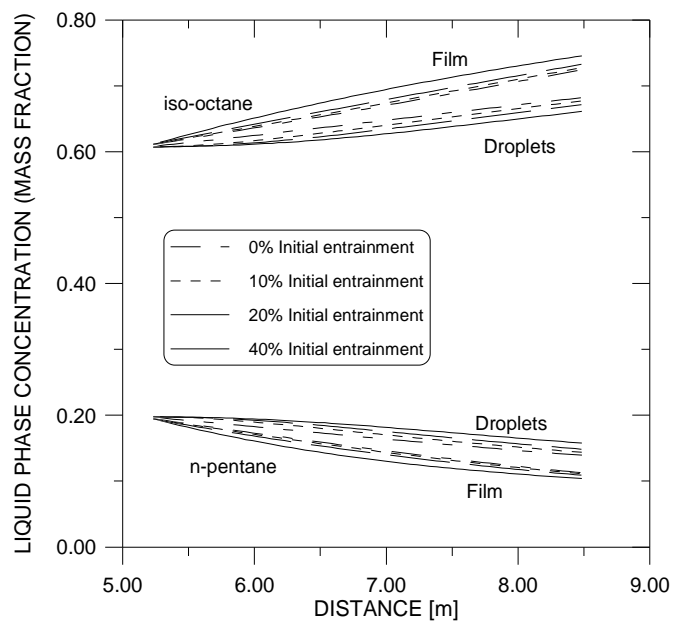

Figure 26. Profiles of mean concentration of $n$-pentane and of iso-octane (mass fraction) in the liquid film and in the liquid droplets. Mixture $0.31 / 0.22 / 0.47$ pentane/hexane/iso-octane (mole fraction), inlet pressure: 2.3 bar, wall heat flux: $40.5 \mathrm{~kW} \mathrm{m-2}$, total mass flux: $297.5 \mathrm{~kg} \mathrm{~m}-2 \mathrm{~s}-1$.

The annular flow methodology was also tested with regard to the prediction of CHF ('dryout') of pure hydrocarbons and mixtures (Barbosa et al., 2000). Figure 30 exhibits an assessment of the ratio of the experimental to predicted $\mathrm{CHF}$ as a function of pressure, inlet 
subcooling, total mass flux and heat flux. As can be seen, the data are predicted in the range of $+/-25 \%$, and no systematic effect is observed for any of the parameters. A significant improvement over existing correlations (Katto and Ohno, 1984) was obtained for pure fluids and for mixtures, as can be seen from Figure 31.

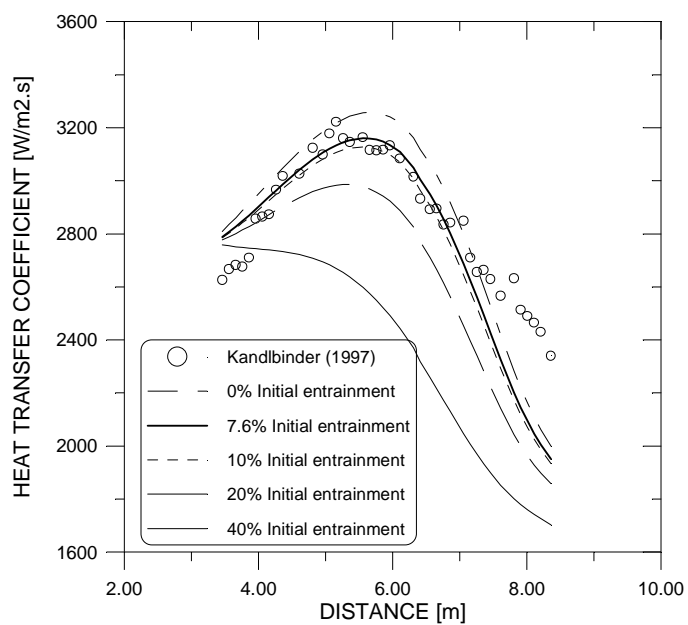

Figure 27. Local heat transfer coefficient prediction as a function of initial entrained fraction. Mixture $\mathbf{0 . 7 / 0 . 3}$ pentane/iso-octane (mole fraction), inlet pressure: 2.3 bar, wall heat flux: $49.8 \mathrm{~kW} \mathrm{m-2,} \mathrm{total} \mathrm{mass} \mathrm{flux:} 292.8 \mathrm{~kg} \mathrm{~m}$ $2 s-1$.

Overall, a simple evaluation of the performance of the improved methodology for mixtures can be devised in terms of the heat transfer coefficient averaged over the portion of the pipe in which annular exists (Barbosa et al., 2002b). In Tables 2 and 3, an assessment of the inclusion of the initial entrained fraction correlation in the calculation methodology is made through a comparison of the parameter $r_{e \%}$ (defined through Eq. 31) for different initial entrained fractions,

$$
r_{e \%}=\frac{\left\langle\bar{\alpha}_{A}\right\rangle}{\left\langle\bar{\alpha}_{\exp }\right\rangle},
$$

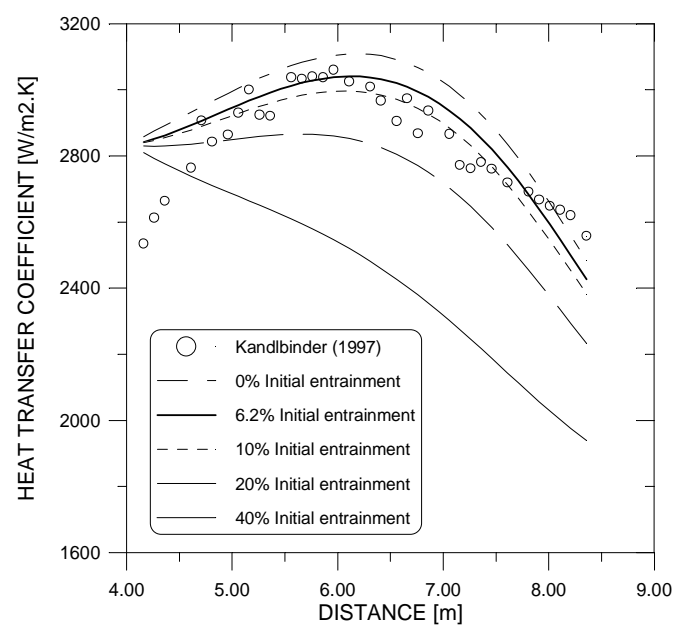

Figure 28. Local heat transfer coefficient prediction. Mixture $0.7 / 0.3$ pentane/iso-octane (mole fraction), inlet pressure: $\mathbf{3 . 2}$ bar, wall heat flux: $49.3 \mathrm{~kW} \mathrm{m-2}$, total mass flux: $305.0 \mathrm{~kg} \mathrm{~m}-2 \mathrm{~s}-1$.

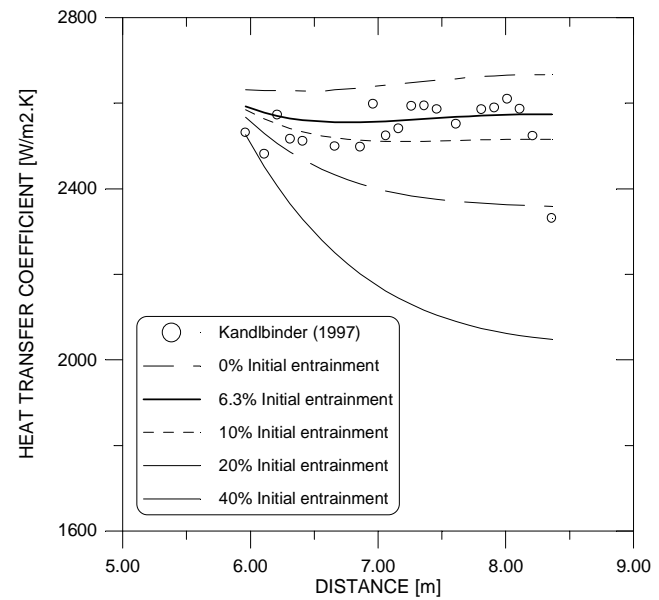

Figure 29. Local heat transfer coefficient prediction. Mixture $0.31 / 0.22 / 0.47$ pentane/hexane/iso-octane (mole fraction), inlet pressure: 3.11 bar, wall heat flux: $38.6 \mathrm{~kW} \mathrm{m-2}$, total mass flux: $304.7 \mathrm{~kg} \mathrm{~m}-2 \mathrm{~s}-1$.

where $\left\langle\bar{\alpha}_{A}\right\rangle$ is the calculated heat transfer coefficient averaged over the length of the pipe over which annular flow takes place. In calculating $\left\langle\bar{\alpha}_{A}\right\rangle$, it is assumed that an entrained fraction $e \%$ is available for evaporation at the onset of annular flow. Analogously, $\left\langle\bar{\alpha}_{\text {exp }}\right\rangle$ is the experimental heat transfer coefficient averaged over the length of the pipe over which annular flow exists. In those tables, $r_{e} \%$ is calculated using the initial entrainment fraction given by the correlation of Barbosa et al. (2002c) and compared with $r_{0 \%}$, $r_{10 \%}, r_{20 \%}$ and $r_{40 \%}$.
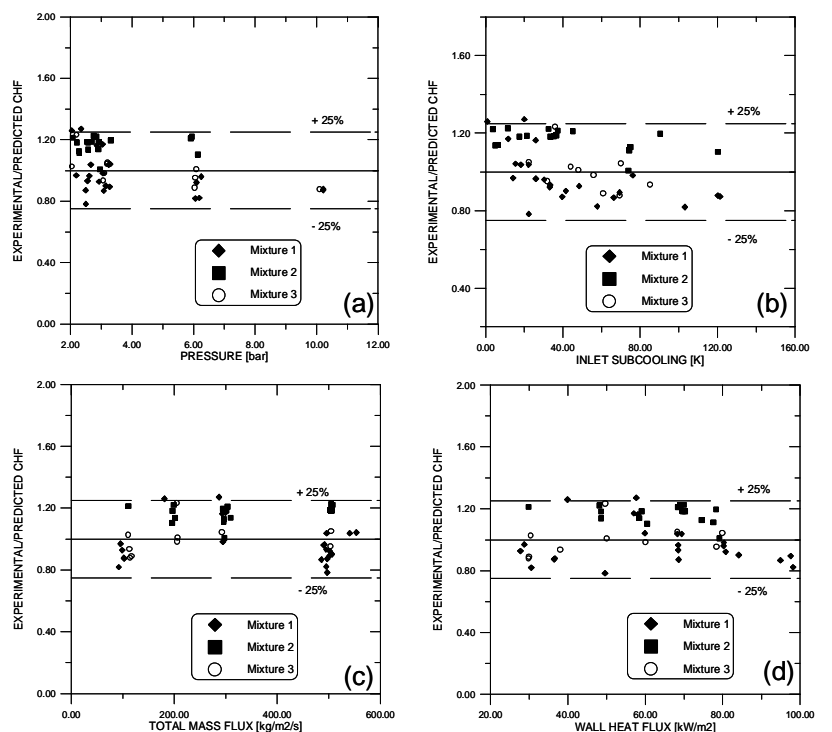

Figure 30. Predictions of CHF in mixtures.

In Tables 2 and 3 , the values of $r$ closest to unity were highlighted for each condition. Although the results obtained using the correlation for entrained fraction provide a good prediction of the experimental data (in terms of the average heat transfer coefficient), they do not correspond to the best estimate for each condition. It does seem that there is an effect of total mass flux and system pressure on the initial entrained fraction which gives the best agreement and this effect is not picked up by the correlation. A 
reason for this may be sought in the effect of physical properties on the initial entrained fraction (viscosity and surface tension are not taken into account by the correlation). It can also be observed that the effect of initial entrained fraction becomes more important with increasing system pressure (Barbosa et al., 2002b).

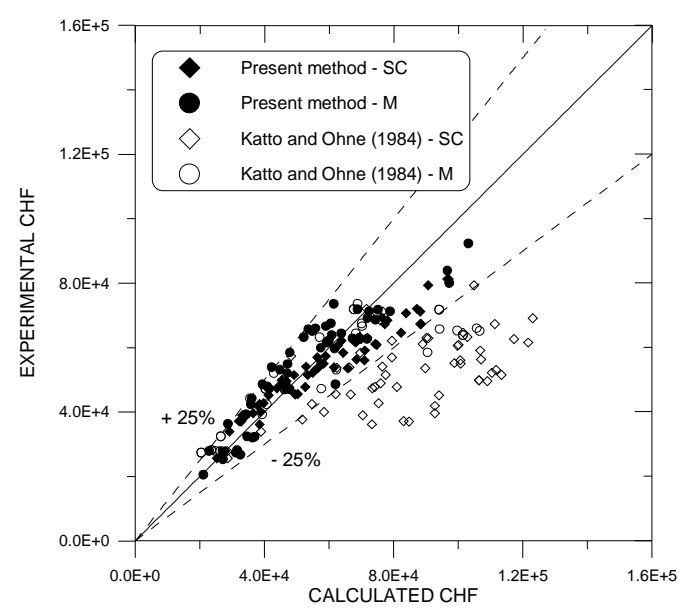

Figure 31. Prediction of CHF for single components (SC) and for mixtures (M).

A subsequent work (Barbosa et al., 2003) looked into the hydrodynamic non-equilibrium (droplet interchange coupled with mixture effects) in condensation of binary and multicomponent mixtures. The key idea is that the same effects responsible for a deterioration of the heat transfer coefficient in boiling would now be resulting in a heat transfer enhancement in condensation. There was some indication in the literature of condensation enhancement in refrigerant mixtures (Cavallini et al., 1999), but there remained the challenge of quantifying the heat transfer gain adequately.

In practice, the effect of droplet interchange on condensation heat transfer is not as pronounced as on boiling due to the contributions of two aspects, (i) typical boiling ranges characteristic of condensation experiments are not as high as those encountered in boiling experiments (Barbosa et al., 2003); (ii) more importantly, in evaporation, diffusive mass transfer and droplet interchange work in the same direction, i.e., towards a deterioration of the heat transfer coefficient. In condensation, however, a possible increase in the heat transfer coefficient associated with droplet interchange may be cancelled out or overcome by the decrease due to mass transfer resistance.

Table 2. Values of $r \%(E q .31)$ for binary mixtures $(0.7 / 0.3$ mole $n$ pentane/iso-octane). Pressure in bar, mass flux in $\mathrm{kg} / \mathrm{m} 2 \mathrm{~s} 1$, heat flux in W/m2. Data of Kandlbinder (1997).

\begin{tabular}{|ccccccccc|}
\hline$p$ & $\dot{m}_{T}$ & $\dot{q}_{w}$ & $e \%$ & $r_{e} \%$ & $r_{0 \%}$ & $r_{10 \%}$ & $r_{20 \%}$ & $r_{40 \%}$ \\
\hline 2.16 & 205.5 & 39.4 & 6.8 & 0.9396 & 0.9605 & 0.9268 & 0.8844 & 0.8423 \\
\hline 2.25 & 288.0 & 39.7 & 7.8 & 1.0107 & 1.0385 & 1.0022 & 0.9618 & 0.8665 \\
\hline 2.49 & 496.8 & 40.1 & 9.6 & 1.1330 & 1.1474 & 1.1324 & 1.1156 & 1.0542 \\
\hline 3.07 & 197.6 & 39.8 & 5.3 & 1.0488 & 1.0652 & 1.0286 & 0.9838 & 0.8893 \\
\hline 3.08 & 301.1 & 39.5 & 6.4 & 1.0242 & 1.0455 & 1.0102 & 0.9707 & 0.8794 \\
\hline 2.85 & 509.8 & 39.9 & 9.0 & 1.0189 & 1.0339 & 1.0174 & 1.0076 & 0.9779 \\
\hline 5.99 & 198.1 & 39.4 & 3.4 & 1.0796 & 1.0937 & 1.0507 & 1.0024 & 0.9018 \\
\hline 5.97 & 300.0 & 39.4 & 4.1 & 1.0507 & 1.0650 & 1.0257 & 0.9819 & 0.8833 \\
\hline 9.96 & 203.4 & 48.8 & 2.5 & 1.1056 & 1.1182 & 1.0655 & 1.0045 & 0.8359 \\
\hline 10.19 & 306.1 & 39.4 & 2.9 & 1.2155 & 1.2309 & 1.1799 & 1.1310 & 1.0099 \\
\hline 10.26 & 508.0 & 49.4 & 3.6 & 1.2641 & 1.2804 & 1.2395 & 1.2045 & 1.1039 \\
\hline
\end{tabular}

Table 3. Values of r\% (Eq. 31) for ternary mixtures $(0.31 / 0.22 / 0.47$ mole $n$ pentane/n-hexane/iso-octane). Pressure in bar, mass flux in $\mathrm{kg} / \mathrm{m} 2 \mathrm{~s} 1$, heat flux in W/m2. Data of Kandlbinder (1997).

\begin{tabular}{|ccccccccc|}
\hline$p$ & $\dot{m}_{T}$ & $\dot{q}_{w}$ & $e \%$ & $r_{e} \%$ & $\eta_{0 \%}$ & $\eta_{0 \%}$ & $r_{20 \%}$ & $r_{40 \%}$ \\
\hline 2.18 & 206.2 & 40.1 & 6.6 & 1.0362 & 1.0693 & 1.0180 & 0.9657 & - \\
\hline 2.43 & 297.5 & 40.5 & 7.5 & 1.0056 & 1.0428 & 0.9932 & 0.9475 & 0.8477 \\
\hline 2.50 & 500.6 & 39.7 & 9.5 & 1.1023 & 1.1425 & 1.1003 & 1.0654 & 0.9854 \\
\hline 3.17 & 204.1 & 49.6 & 5.1 & 1.1145 & 1.1424 & 1.0926 & 1.0387 & 0.9442 \\
\hline 3.11 & 304.7 & 38.7 & 6.3 & 1.0135 & 1.0477 & 0.9966 & 0.9542 & 0.8690 \\
\hline 3.10 & 503.4 & 39.4 & 8.0 & 1.0765 & 1.1141 & 1.0682 & 1.0296 & 0.9456 \\
\hline 6.11 & 208.1 & 38.9 & 3.3 & 1.0992 & 1.1171 & 1.0626 & 1.0144 & 0.9081 \\
\hline 6.02 & 304.6 & 38.6 & 4.0 & 1.1427 & 1.1643 & 1.1143 & 1.0713 & 0.9797 \\
\hline 5.91 & 505.9 & 39.5 & 5.1 & 1.1740 & 1.1949 & 1.1520 & 1.1240 & 1.0677 \\
\hline 10.23 & 199.2 & 39.0 & 2.3 & 0.9253 & 0.9350 & 0.8928 & 0.8520 & 0.7364 \\
\hline 10.05 & 308.3 & 38.2 & 2.9 & 1.1815 & 1.2000 & 1.1423 & 1.0975 & 0.9935 \\
\hline 10.16 & 506.0 & 50.0 & 3.5 & 1.3186 & 1.3426 & 1.2688 & 1.2321 & 1.1518 \\
\hline
\end{tabular}

Figures 32 and 33 illustrate variations of liquid film and droplets mean concentration for boiling and condensation, respectively (Barbosa et al., 2003). Figure 32 represents an actual experimental condition (boiling) analysed by Kandlbinder (1997), whereas the condition depicted in Figure 33 is a 'numerical' condensation experiment with identical conditions. Zero initial entrained droplet fraction was assumed in both cases. As can be seen, the difference in concentration between film and droplets is not as high in condensation as it is in boiling due to different 'directions' of droplet interchange and mass transfer resistance with regard to heat transfer behaviour. Finally, Figure 34 exhibits a comparison between predicted and experimental local heat transfer coefficients (Cavallini et al., 1999) for convective condensation of R407-C (a non-azeotropic ternary refrigerant mixture). Again, agreement with the experimental data is encouraging.

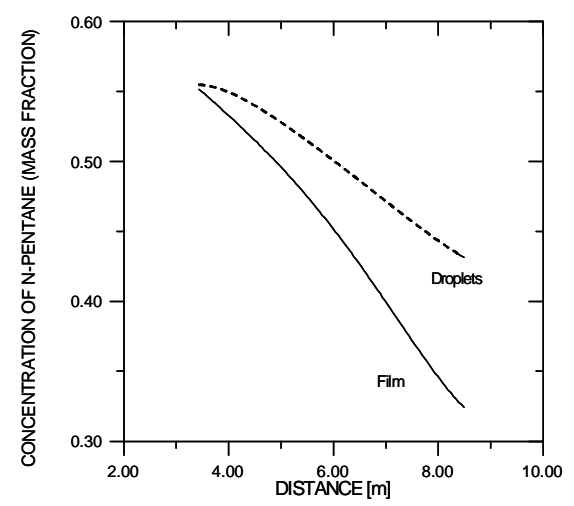

Figure 32. Liquid and droplets concentration in boiling. Mixture $0.7 / 0.3$ pentane/iso-octane (mole fraction), inlet pressure: 2.3 bar, wall heat flux: $49.8 \mathrm{~kW} \mathrm{m-2}$, total mass flux: $292.8 \mathrm{~kg} \mathrm{~m}-2 \mathrm{~s}-1$.

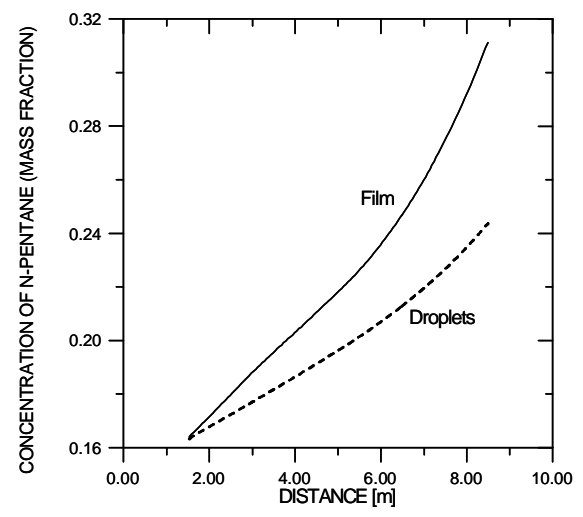

Figure 33. Liquid and droplets concentration in condensation (hypothetical case). Mixture $\mathbf{0 . 7 / 0 . 3}$ pentane/iso-octane (mole fraction), inlet pressure: $2.3 \mathrm{bar}$, wall heat flux: $49.8 \mathrm{~kW} \mathrm{m-2}$, total mass flux: 292.8 kg m-2s-1. 


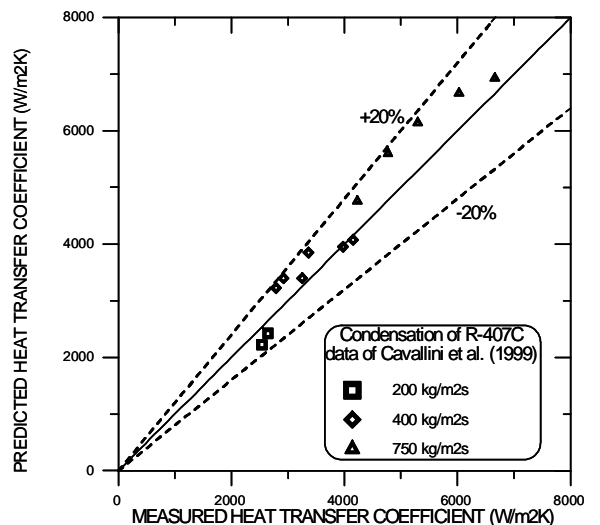

Figure 34. Prediction of forced convective condensation of R-407C.

\section{Conclusions}

Recent advances in modelling of convective phase change flows were addressed in this lecture, emphasizing the description of macroscopic thermodynamic and hydrodynamic non-equilibrium phenomena.

In the first case of non-equilibrium modelling reviewed here, a model was presented to predict heat transfer coefficient peaks observed in the near-zero quality region in boiling of hydrocarbons (Kandlbinder, 1997; Urso et al., 2002). The kernel of the model was the occurrence of instabilities leading to the formation of a nonequilibrium slug flow regime in which the Taylor bubbles are separated by subcooled liquid slugs (Barbosa and Hewitt, 2004).

The non-equilibrium slug flow model is the first model to predict the experimental trends of heat transfer (i.e., peaks). The heat transfer coefficient peaks coincide with peaks in the (calculated) difference between the equilibrium bulk and the average slug body temperatures. There is, therefore, an indication that the slugs remain subcooled for distances longer than would be the case in equilibrium flows. The net result is a lower calculated wall temperature in the slug region, leading to an increase in the heat transfer coefficient calculated through Eq. (1).

In the second case, an extensive annular flow calculation methodology based on local mass, momentum and energy balances in the three fields, viz., film, droplets and vapour, was reviewed. This was also a pioneering methodology in predicting the heat transfer deterioration observed at high qualities in boiling of mixtures. The differences between the non-equilibrium methodology and the 'classical' (equilibrium) prediction methods arise mainly from two causes. Firstly, differences in concentration are developed between the entrained droplets and the liquid film as a result of different phase change driving forces imposed to the two streams (in contrast, traditional methods implicitly assume that concentration is unique in the liquid phase). Secondly, complex interfacial heat and mass transfer interactions give rise to temperature differences between the film interface and the vapour core. An association of these two phenomena explain the deterioration observed in the heat transfer coefficient in boiling and, to some extent, an enhancement in heat transfer in condensation.

\section{Acknowledgements}

The author thanks Prof. G.F. Hewitt, FRS, FREng (Imperial College) for encouragement and stimulating discussions. The financial support of CNPq and FUNCITEC (Santa Catarina) is also acknowledged.

\section{References}

Azzopardi, B.J., Freeman, G. and King D.J., Drop sizes and deposition in annular two-phase flow, UKAEA Report AERE-R9634, 1980.

Baehr, H. D. and Stephan, K., Heat and Mass Transfer, SpringerVerlag, Berlin, 1998.

Barbosa, Jr., J.R., Phase Change of Pure Fluids and Mixtures in Annular Flow, Ph.D. thesis, Imperial College, London, 2001.

Barbosa, Jr., J.R. and Hewitt, G.F., A model for convective boiling of ternary mixtures, Proc. $6^{\text {th }}$ UK National Heat Transfer Conference, pp. 169174, Edinburgh, UK, 1999.

Barbosa, Jr., J.R. and Hewitt, G.F., Forced convective boiling of binary mixtures in annular flow. Part I: Liquid phase mass transport, International Journal of Heat and Mass Transfer 44, pp. 1465-1474, 2001a.

Barbosa, Jr., J.R. and Hewitt, G.F., Forced convective boiling of binary mixtures in annular flow. Part II: Heat and mass transfer, International Journal of Heat and Mass Transfer 44, pp. 1475-1484, $2001 \mathrm{~b}$.

Barbosa, Jr., J.R. and Hewitt, G.F., A thermodynamic non-equilibrium slug flow model, Journal of Heat Transfer - Transactions of the ASME, in press, 2004.

Barbosa, Jr., J.R., Kandlbinder, T.K. and Hewitt, G.F., A study of dryout in annular flow of single component hydrocarbons and their mixtures, Multiphase Science and Technology 12(3/4), pp. 265-293, 2000.

Barbosa, Jr., J.R., Kandlbinder, T.K. and Hewitt, G.F., Forced convective boiling of ternary mixtures at high qualities, International Journal of Heat and Mass Transfer 45, pp. 2655-2665, 2002a.

Barbosa, Jr., J.R., Hewitt, G.F. and Richardson, S.M., Improved annular flow modelling of pure fluids and multicomponent mixtures, Chemical Engineering Research and Design, Transactions of the IChemE, 80, Part A, pp. 261-266, 2002b.

Barbosa, Jr., J.R., Hewitt, G.F., König, G. and Richardson, S.M., Liquid entrainment, droplet concentration and pressure gradient at the onset of annular flow in a vertical pipe. International Journal of Multiphase Flow 28, pp. 943-961, 2002c.

Barbosa, Jr., J.R., Hewitt, G.F. and Richardson, S.M., A note on the influence of droplet interchange on evaporation and condensation of multicomponent mixtures in annular flow, International Journal of Heat and Mass Transfer 46, pp. 2505-2509, 2003.

Barnea, D. and Yacoub, N., Heat transfer in vertical upwards gas-liquid slug flow, International Journal of Heat and Mass Transfer 26, pp. 13651376, 1983.

Bird, R.B., Stewart, W.E. and Lightfoot, E.N., Transport Phenomena, John Wiley \& Sons, New York, 1960.

Butterworth, G. and Shock, R.A.W., Flow Boiling, Proc. $7^{\text {th }}$ International Heat Transfer Conference, Munich, Vol. 1, pp. 11-30, 1982.

Cavallini, A., del Col, D., Doretti, L., Longo, G.A., Rossetto, L. Condensation of R-22 and R-407C inside a horizontal tube, Proc. $20^{\text {th }}$ International Congress of Refrigeration, IIR/IIF, Sydney, Australia, 1999.

Celata, G.P., Cumo, M. and Setaro, T., A review of pool and forced convective boiling of binary mixtures, Experimental Thermal and Fluid Science 9, pp. 367-381, 1994.

Cheah, L.W., Forced Convective Evaporation at Sub-atmospheric Pressure, Ph.D. thesis, Imperial College, University of London, 1995.

Chen, J.C., A Correlation for Boiling Heat Transfer to Saturated Fluids in Convective Flow. Industrial and Engineering Chemistry: Process Design Develop., vol. 5(3), pp. 322-329, 1966.

Chun, K.R. and Seban, R.A., Heat Transfer to Evaporating Liquid Films, Journal of Heat Transfer - Transactions of the ASME, vol. 93 pp.391-396, 1971.

Collier, J.G. and Thome, J.R, Convective Boiling and Condensation, $3^{\text {rd }}$ Ed. Oxford University Press, 1994.

De Cachard, F. and Delhaye, J.M., A Slug-Churn Flow Model for Small-Diameter Airlift Pumps, International Journal of Multiphase Flow, vol. 22(4), pp. 627-649, 1996.

Fernandes, R.C., Semiat, R. and Dukler, A.E., Hydrodynamic Model for Gas-Liquid Slug Flow in Vertical Tubes. AIChE Journal, vol. 29(6), pp. 981-989, 1983.

Fuller, E., Schettler, P.D. and Giddings, J.C., A new method for prediction of binary gas-phase diffusion coefficients, Industrial Engineering Chemistry, 58(5), pp. 19-23, 1964.

Govan, A.H., Modelling of Vertical Annular and Dispersed Two-Phase Flows, Ph.D. thesis, Imperial College, London, 1990.

Govan, A.H., Hewitt, G.F., Owen, D.G. and Bott, T.R., An improved CHF modelling code, Proc. $2^{\text {nd }}$ UK National Heat Transfer Conference, pp. 33-48, London, UK, 1988

Hawkes, N.J., Wispy-Annular Flow, Ph.D. thesis, Imperial College, London, 1996. 
Hewitt, G.F., Challenges in Boiling Research, Keynote Lecture, Boiling 2000: Phenomena and Emerging Applications, UEF, April 30-May 5, Anchorage, AK, 2000

Hewitt, G.F. and Hall-Taylor, N.S., Annular Two-Phase Flow, Pergamon Press, 1970

Hewitt, G.F., Shires, G.L. and Bott, T.R., Process Heat Transfer, CRC Press, Florida, 1994

Jayanti, S. and Hewitt, G.F., Prediction of the Slug-to-Churn Transition in Vertical Two-Phase Flow, International Journal of Multiphase Flow, vol. 18(6), pp. 847-860, 1992.

Jeglic, F.A. and Grace, T.M., Onset of Flow Oscillations in Forced Flow Subcooled Boiiling. NASA Technical Note TN D-2821, Lewis Research Center, Cleveland, Ohio, USA, 1965.

Kandlbinder, T.K., Experimental Investigation of Forced Convective Boiling of Hydrocarbons and Hydrocarbon Mixtures, Ph. D. thesis, Imperial College, 1997.

Kandlikar, S., A General Correlation for Saturated Two-Phase Flow Boiling Heat Transfer Inside Horizontal and Vertical Tubes. Journal of Heat Transfer, vol. 112, pp. 219-228, 1990.

Kattan, N., Thome, J.R. and Favrat, D., R-502 and Two NearAzeotropic Alternatives: Part I - In-Tube Flow Boiling Tests. ASHRAE Transactions, vol. 101, Part 1, pp. 491-508, 1995.

Katto, Y. and Ohno, H., An improved version of the generalised correlation of critical heat flux for forced convective boiling of uniformly heated vertical tubes, International Journal of Heat and Mass Transfer 27, pp. 1641-1648, 1984.

Orell, A. and Rembrand, R., A Model for Gas-Liquid Slug Flow in a Vertical Tube. Industrial and Engineering Chemistry: Fundamentals, vol. 25, pp. 196-206, 1986.

Palen, J.W., Shell-and-Tube Reboilers: Thermal Design, in: G.F. Hewitt (Ed.), Handbook of Heat Exchanger Design, Begell House, New York, pp. 3.6.2-1 - 3.6.2-12, 1992 .

Saha, P. and Zuber, N., Point of Net Vapor Generation and Vapor Void Fraction in Subcooled Boiling, Proc. $5^{\text {th }}$ International Heat Transfer Conference, Tokyo, Paper B4.7, 1974.

Shah, M.M., Chart Correlation for Saturated Boiling Heat Transfer: Equations and Further Study. ASHRAE Transactions, vol. 88(1), pp. 185$196,1982$.
Shatto, D.P., Vertical In-Tube Flow Boiling of Mixtures, Ph.D. thesis, Texas A\&M University, 1998.

Steiner, D. and Taborek, J., Flow Boiling Heat Transfer in Vertical Tubes Correlated by an Asymptotic Model. Heat Transfer Engineering, Vol. 13(2), pp. 43-69, 1992.

Shock, R., Evaporation of binary mixtures in upward annular flow, International Journal of Multiphase Flow 2, pp. 411-433, 1976.

Sun, G., Hewitt, G.F. and Wadekar, V.V., A heat transfer model for slug flow in a horizontal tube, International Journal of Heat and Mass Transfer 47, pp. 2807-2816, 2004.

Sylvester, N.D., A Mechanistic Model for Two-Phase Vertical Slug Flow in Pipes. Journal of Energy Resources Technology, vol. 109, pp. 206213, 1987.

Taylor, R. and Krishna, R., Multicomponent Mass Transfer, John Wiley $\&$ Sons, New York, 1993.

Thome, J.R., Flow Boiling in Horizontal Tubes: A Critical Assessment of Current Methodologies. Proc. $1^{\text {st }}$ Symposium on Two-Phase Flow Modelling and Experimentation Conference, Vol. 1., pp 41-52, 1995.

Thome, J.R. and Shock, R., Boiling of multicomponent liquid mixtures, Advances in Heat Transfer 16, pp. 59-156, 1984.

Urso, M.E., Wadekar, V.V. and Hewitt, G.F., Flow Boiling at Low Mass Flux, Proc. $12^{\text {th }}$ International Heat Transfer Conference, Grenoble, pp. $803-$ 808, 2002.

Wadekar, V.V., Convective heat transfer to binary mixtures in annular two-phase flow, HTFS RS AERE R13815, 1990.

Wadekar, V.V. and Kenning, D.B.R., Flow Boiling Heat Transfer in Vertical Slug and Churn Flow Region, Proc. $9^{\text {th }}$ International Heat Transfer Conference, Jerusalem, Vol. 3, pp. 449-454, 1990.

Wallis, G.B., One Dimensional Two-Phase Flow, Mc-Graw-Hill, New York, 1969.

Webb, D.R., Heat and mass transfer in condensation of multicomponent vapours, Proc. $7^{\text {th }}$ International Heat Transfer Conference, pp. 167-174, Munich, 1982

Webb, R.L. and Gupte, N.S., A critical review of correlations for convective vaporization in tubes and tube banks, Heat Transfer Engineering 13 , pp. $58-81,1992$.

Wettermann, M. and Steiner, D., Flow boiling heat transfer characteristics of wide-boiling mixtures, International Journal of Thermal Sciences 39 , pp. 225-235, 2000 